\title{
Kazantzakis y Scorsese, dos autores frente a la controversia: La última tentación (de Cristo)
}

\section{Kazantzakis and Scorsese, Two Creators Against Controversy: The Last Temptation (of Christ)}

\author{
Miguel Dávila Vargas-MachuCa \\ Universidad Internacional de Andalucía \\ mdavilavm@gmail.com \\ ORCID ID: 0000-0001-7442-4509
}

\begin{abstract}
Resumen: El escritor cretense Nikos Kazantzakis mantuvo a lo largo de su vida un continuo interés en la figura de Cristo, lo que también tuvo su plasmación en su carrera literaria. Una de sus obras principales, la novela La última tentación, abordaba de una manera moderna y heterodoxa los hechos de la vida de Jesús de Nazaret, generando gran polémica en múltiples sectores de diversas religiones. Tiempo después el director de cine estadounidense Martin Scorsese debió afrontar numerosos problemas y retrasos para adaptar la novela a la gran pantalla. Y, cuando finalmente consiguió estrenar La última tentación de Cristo, la polémica también lo alcanzó a él y a su película, aunque el paso del tiempo ha ido relajando unas reacciones más fanáticas que reflexionadas.
\end{abstract}

Palabras clave: adaptación cinematográfica, Martin Scorsese, Nikos Kazantzakis, Cristo, religión, polémica.

\begin{abstract}
The Cretan writer Nikos Kazantzakis had a continuous lifelong interest in the figure of Christ, which also had an influence on his literary career. One of his principal works, the novel The Last Temptation, was a modern and heterodox approach to the facts surrounding the life of Jesus of Nazareth's, generating massive controversy in many sections of the world's religions. Later, the American film director Martin Scorsese faced many problems and schedule delays while trying to adapt the novel for the big screen. And when he finally completed The Last Temptation of Christ, the controversy extended to him and his movie, though the passing of time has eased reactions that were more fanatical than considered.
\end{abstract}

Key Words: film adaptation, Martin Scorsese, Nikos Kazantzakis, Christ, religion, controversy. 


\section{KAZANTZAKIS Y SU VISIÓN DE LA RELIGIÓN Y DE CRISTO}

Nikos Kazantzakis (1883-1957) es uno de los escritores griegos modernos más conocidos y algunas de sus obras resuenan poderosamente en el imaginario colectivo mundial. El mayor eco de su producción literaria proviene principalmente de sus novelas, muchas de las cuales serían posteriormente recogidas y adaptadas por otros medios narrativos, como el teatral, el televisivo o el cinematográfico: Vida y hechos de Alexis Sorbás (Bíos ke politía tu Alexi Zorbá, 1946), Cristo de nuevo crucificado (O Jristós xanastavrónete, 1948), El Capitán Mijalis (Kapetán Mijalis, 1950), La última tentación (O Teleftéos Pirasmós, 1951), Informe al Greco (Anaforá ston Greko, 1961).

Una de las constantes en la producción de Kazantzakis es su continuo interés en la religión y, más concretamente, en la figura de Cristo. Criado en un ambiente familiar cristiano ortodoxo, su infancia y juventud se caracterizaron por unas profundas convicciones religiosas, pero su formación vital e intelectual fue añadiendo otros aspectos que de algún modo provocaron una reacción frente a ese fervor inicial y configuraron su peculiar sistema de pensamiento. El literato cretense unió en su cosmos filosófico personal tanto ese sentido religioso amasado desde su infancia como otras diferentes y variadas posturas ideológicas: «nacionalismo, creencia en el superhombre, socialismo, fascismo, incluso un comunismo revestido de santidad que le lleva a mezclar a Cristo, Buda y Lenin» (Vilela Gallego, 2015: 11). Semejante mezcla daría como resultado por fuerza un sistema de creencias personal caracterizado por una fe religiosa heterodoxa que no atendía a los cánones cristianos, pero que tampoco abandonó nunca la búsqueda mística de la figura de Dios. No hablamos por tanto de un ateo, ya que se mantuvo permanentemente interesado en la esencia divina, creyendo en su existencia y sin dejar de buscarla por doquier, una angustia vital que le acompañaría siempre, aunque ciertamente rechazara la postura oficial de la Iglesia:

Pese a que Casandsakis perdió la fe, siempre mantuvo una perspectiva espiritual, nunca se hizo ateo, jamás renunció a una peculiar forma de creencia en lo divino [...]. tampoco negó la religión en sí misma, lo que rechazó fue la religión que la Iglesia oficial le ofrecía, «un caramelo para endulzar conciencias» (Vilela Gallego, 2015: 25).

En este sentido, para configurar su particular visión de lo divino, el cretense se dedicó a estudiar tanto la propia religión cristiana, incluyendo

\footnotetext{
${ }^{1}$ Las fuentes principales manejadas para este apartado y el siguiente son Vilela Gallego, 2015, y Stavru, 2015. Para evitar demasiadas referencias, se reflejan solo sus citas. Remito también a los datos biográficos y sobre el pensamiento religioso de Kazantzakis en los otros artículos de este monográfico, a cargo de Helena González Vaquerizo, Amor López Jimeno y Alejandro Valverde García.
} 
viajes a lugares santos como el Monte Atos y los Santos Lugares en Palestina, como otras filosofías y religiones, entre ellas el budismo.

Partiendo de estas premisas religioso-ideológicas, Kazantzakis otorgó un gran protagonismo a la lucha interior del ser humano entre lo material y lo espiritual. Por extensión, su interés religioso derivará en una obsesión por la figura de Cristo, en tanto mezcla de divinidad y de humanidad y como símbolo del sacrificio vital hasta alcanzar una muerte que constituiría «la consumación de nuestra lucha, la culminación de la vida, ya que al inmovilizar la materia, libera a la energía primigenia (el élan vital) del peso material, dejándola libre para regenerarse una vez más» (Vilela Gallego, 2015: 31). El autor cretense creía que, tras pasar por diversas etapas y necesarios sacrificios en la vida, el ser humano se desprendería de la materia carnal para alcanzar su triunfo espiritual. Por ello, la figura de Cristo es para él «la quintaesencia de los símbolos de la sociedad contemporánea, $[\ldots]$ el modelo de héroe combatiente que pasa por todas las etapas que exige la transformación de la carne en espíritu» (Vilela Gallego, 2015: 36).

Evidentemente, todo este interés tan acusado en la religión tuvo consecuencias y plasmación directa en su producción literaria. Para el cretense, abordar a Cristo en sus obras era una liberación personal, una especie de catarsis para superar esa tortura interior desarrollada a través de la búsqueda continua de lo divino. De hecho, Cristo era uno de los diversos símbolos (junto a Odiseo, Alexis Zorba o Lenin) a los que recurrió en su obra para escenificar su optimismo respecto a la religión, «la creencia en que el espíritu triunfará a pesar de todas las adversidades» (Vilela Gallego, 2015: 34). Pero hay que recordar que, si bien la religión fue siempre una obsesión para Kazantzakis, él rechazaba la doctrina oficial de la Iglesia, sobre todo en lo tocante al interés eclesiástico preferente por el más allá y no por lo terrenal, mientras que él prefería «bajar a Cristo -el espíritu- del cielo y presentarlo como su antítesis, la materia, y superar la contradicción: el Cristo material seguirá un camino ascendente hasta desmaterializarse por completo y transformarse en puro espíritu» (Vilela Gallego, 2015: 37).

Antes de que viera la luz la novela que centra este texto, Kazantzakis ya había tratado a Cristo en varias ocasiones, en las cuales de hecho ya se apuntan algunas de sus características, como podrá comprobarse más adelante. La primera de ellas es la tragedia teatral Cristo (Jristós, 1928), que comenzó su gestación en 1915 y puede considerarse «un clarísimo preludio de La última tentación» (Vilela Gallego, 2015: 38), ya que en ella Cristo enfrenta sus esencias divina y humana para conseguir el triunfo espiritual, y en su resurrección no hay una intervención divina, sino de María Magdalena, un símbolo de lo terrenal y lo carnal, e incluso erótico. La siguiente es la tertsina (o terceto) homónima a la obra anterior, publicada en 1937, en la que se vuelven a confrontar la idea de la vida más allá de la muerte propugnada por el cristianismo oficial con la de la 
existencia humana terrenal; en ella se muestra a Cristo en el desierto enfrentándose a la tentación del deseo carnal hacia una mujer semidesnuda y apelando a la compasión de Dios para poder superarla. En el poema épico Odisea (Odisseia, 1938), considerado por el propio Kazantzakis como su obra cumbre, la figura de Cristo se personifica en un joven pescador negro con el que se encuentra Odiseo, y entre ambos se escenifica de nuevo el enfrentamiento entre la vida más allá de la muerte y la vida terrenal, siendo esta última la vencedora en opinión del héroe griego, que «manifiesta, arrogante, que su espíritu no tiene necesidad de bálsamos» (Vilela Gallego, 2015: 41). La última obra de Kazantzakis que trata la figura de Cristo antes de la edición de La última tentación es la novela Cristo de nuevo crucificado, que comportaba una transposición de la Pasión de Cristo en clave contemporánea, y que sería adaptada a la gran pantalla por Jules Dassin en El que debe morir (Celui qui doit mourir, 1957)2 ${ }^{2}$.

\section{LA NOVELA: LA ÚLTIMA TENTACIÓN}

Después de haber tratado la religión y la figura de Cristo en diversas obras, resultaba inevitable que Nikos Kazantzakis decidiera aportar su visión particular y crear una novela centrada en la propia vida de Jesús de Nazaret:

La primera vez que Nicos Casandsakis pensó en escribir este libro sobre la vida novelada de Cristo fue durante la ocupación alemana, en mayor de 1942, en Egina, donde el escritor cretense vivió aproximadamente veinte años, de 1926 a 1946. Lo titularía Las Memorias de Cristo (Stavru, 2015: 727).

La decisión del cretense, establecido entonces en la isla griega de Egina, se convirtió en una gestación madurada durante años, hasta que en 1950, ocho años después de haber mencionado la idea de la novela, inicia su escritura durante su estancia en Antibes, en la Costa Azul francesa. El título planteado inicialmente de Las Memorias de Cristo fue sustituido por el de La última tentación ( $O$ Teleftéos Pirasmós), y el proceso de escritura culminó con la última redacción de la extensa novela ${ }^{3}$ al año siguiente, en 1951, cuando Kazantzakis contaba con 68 años de edad y seis años antes de su fallecimiento. De hecho, esta visión novelada particular y personal resultaría ser la última ocasión en la que el escritor cretense se acercó a la figura de Cristo en su carrera literaria.

Llegado el momento de lanzar al público la obra, la tarea no resultó nada fácil, dado el contenido heterodoxo de la misma, que comenzó a levantar ampollas en diversos foros antes incluso de salir a la luz. La

\footnotetext{
${ }^{2}$ Para más información sobre esta novela y su adaptación cinematográfica, vid. el artículo de Amor López Jimeno en este mismo monográfico.

3 En la edición española manejada (Kazantzakis, 2015) su extensión roza las seiscientas páginas.
} 
búsqueda de un editor en Grecia comenzó nada más finalizada la novela, pero diversos condicionantes hicieron poco recomendable la edición en el país durante cierto tiempo, aunque hacia 1953 la obra ya había sido traducida a otros idiomas y editada en países como Suecia o Noruega. Pero antes siquiera de ser editada en el propio país de Kazantzakis, en mayo de 1954 le llegaron noticias desde Alemania de que el contenido de la misma había provocado su inclusión por el Papa de Roma (por entonces Pío XII) en el Index librorum prohibitorum, la lista de libros prohibidos por la Iglesia, vigente desde el siglo XVI hasta 1966, un hecho que causó la ira de Kazantzakis, quien calificó la decisión como hipócrita. La publicación de la obra en Grecia tuvo lugar finalmente a través de la editorial Difros, propiedad de Manis Gudelis, quien ya había publicado en 1954 Cristo de nuevo crucificado, sufriendo por ello ciertos contratiempos ${ }^{4}$. Con semejante perspectiva previa, la decisión de editar otra novela de Kazantzakis no fue nada fácil para Gudelis, quien fue amenazado por la Iglesia de Grecia con la excomunión si la publicaba. Pero, a pesar de estos y otros obstáculos, la decisión de Gudelis permitió que La última tentación viera la luz en Grecia en 1955, causando gran sensación.

Pero, epor qué tanto escándalo, tantos obstáculos previos, tantas reacciones polémicas alrededor de esta obra de Kazantzakis? Evidentemente, la respuesta es por sus implicaciones religiosas e incluso sociopolíticas, por constituir una peculiar y heterodoxa biografía de un personaje tan difícil de abordar con libertad o, mejor dicho, tan difícil de sacar de los dogmas establecidos. Como ya se ha mencionado, el escritor cretense no era un ateo, sino un estudioso interesado en diversas facetas de la religión (y no solo la judeocristiana), y en especial en la figura de Cristo, a la que persiguió a lo largo de su carrera literaria. No es de extrañar por tanto que se lanzara a escribir su visión cristológica atendiendo a diversas fuentes literarias dentro y fuera de los cánones religiosos cristianos para crear una base sólida sobre la que cimentar su propia versión. Como culminación de las prolongadas reflexiones de Kazantzakis sobre Cristo, al sobrepasar los límites establecidos por la Iglesia cristiana, La última tentación rompió con lo dogmático y resultó incómoda para los poderes religiosos:

En esta particular biografía literaria de la figura de Cristo que mantiene el equilibrio entre el mito y la historia, entre la filosofía y la teología, Casandsakis ha utilizado de forma magistral y original los textos paleo y neotestamentarios, combinándolos con las conclusiones de la investigación histórica, para presentar un reto a los mitos oficiales de la Iglesia cristiana, ofreciendo su propia idea de la persona y el mensaje de Jesús. Pero esta interpretación personal, aunque basada en los textos $-\mathrm{o}$

\footnotetext{
${ }^{4}$ «La edición de Cristo de nuevo crucificado, llevada a cabo poco antes por el propio Gudelis, había provocado una terrible oposición; la retiraban de las librerías» (Vilela Gallego, 2015: 43)
} 
quién sabe si precisamente por ello- está plagada de concepciones heterodoxas, heréticas y hasta paganas desde el prisma del dogma cristiano oficial (Vilela Gallego, 2015: 57).

Más allá de la Biblia, de la cual hay evidentes ecos en la novela, pueden mencionarse como fuentes a las que recurrió Kazantzakis diversos escritos religiosos apócrifos y heréticos de los primeros siglos del cristianismo ${ }^{5}$, así como obras teológicas tales como Contra las herejías, tratado escrito en el siglo II por Ireneo de Lyon y primera gran fuente eclesiástica para acercarse a muchas de las herejías iniciales, sobre todo los gnósticos. De entre la investigación histórica disponible en el momento en que redactó la novela, pueden ser mencionados estudios sobre los orígenes del cristianismo o reflexiones biográficas sobre la veracidad o falsedad de la existencia de Cristo, como la Vida de Jesús (Historia del cristianismo, tomo I, 1863) de Ernest Renan o Los grandes iniciados (1889) de Edward Schuré. Por último, desde el ámbito de la ficción, pudieron influir también en la novela Memorias de Judas (1870) de Ferdinando Petrucelli della Grattina o «El milagro secreto» (1943) y «Tres versiones de Judas» (1944), relatos recogidos en la obra Ficciones de Jorge Luis Borges.

La última tentación es una narración ficticia de la vida de Cristo que parte de los testimonios evangélicos canónicos del Nuevo Testamento, pero planteada desde la peculiar visión que Kazantzakis tenía de él. La narración comienza con Jesús siendo despreciado por colaborar con los ocupantes romanos al construir las cruces con las que ajustician a los rebeldes. El humilde y atribulado carpintero sufre tormentos físicos, pero también psíquicos, ya que en su interior siente que Dios tiene un plan para él, quizá el de ser el Mesías, aunque no es capaz de discernir si las voces que le acosan o las garras que se le clavan en la cabeza son divinas (en principio positivas) o diabólicas (negativas). El zelote Judas es enviado para matar a Jesús, pero el estado de crispación del carpintero le hace pensar que probablemente sea el Mesías que liberaría a Israel del yugo de los romanos. Judas decide no asesinarle y mantenerse junto a él, vigilándole para que no se desvíe de su sagrada misión mesiánica, a pesar de que ambos discrepen en la forma de ejercerla, ya que el zelote quiere la libertad para Israel mediante el odio, la fuerza y la libertad terrenal, mientras que el carpintero aboga por la libertad del alma a través del amor. Entre los múltiples tormentos de Jesús está su relación con Magdalena, un amor de juventud que terminó cuando él le dio de lado, desgarrando el corazón de la mujer; cuando él acude a su prostíbulo en busca de alguna señal sobre lo que le está ocurriendo, Magdalena reacciona de manera violenta y no le perdona que Dios le apartara de ella hace tiempo, pero Jesús exime de responsabilidad a la divinidad y se

\footnotetext{
${ }^{5}$ Entre ellos, el Evangelio de Judas, el Protoevangelio de Santiago, el Evangelio del Pseudo Mateo, el Libro de la infancia del Salvador, el Evangelio armenio de la Infancia o el Evangelio de Bartolomé (Vilela Gallego, 2015: 45, nota 60, y 81).
} 
autoinculpa. El camino emprendido por Jesús en busca de respuestas muestra sus temores, sus dudas sobre si Dios es realmente su propio miedo, y si, en lugar de bendecirle, quiere acabar con él. Poco después, ante la condena a lapidación de María Magdalena por haber infringido la ley sagrada trabajando (acostándose con romanos) en sabbath, Jesús reacciona advirtiendo sobre el necesario perdón y comienza su predicación, siendo seguido desde entonces por algunos discípulos que aún no tienen muy claro cuál es su misión, mientras Judas acecha amenazante al grupo. Una de las primeras grandes pruebas para Jesús es su encuentro con Juan el Bautista para confirmar si es el Mesías, dando lugar a una discusión sobre la misión mesiánica, entre la perspectiva violenta y vengativa por parte de Juan y la apuesta por el amor y la fraternidad por parte de Jesús. Este decide por fin encontrarse a sí mismo y descifrar las respuestas que necesita sobre su relación con Dios, para lo cual se retira al desierto. Allí sufrirá diversas tentaciones por parte del diablo, que le aconseja buscar una mujer y formar una familia según los designios de Dios. Pero Jesús resiste y una visión de Juan el Bautista le conmina a reaccionar de forma violenta contra Satanás. Al volver del desierto, Jesús es reconfortado en Betania, en casa de María y Marta, las hermanas de Lázaro, quienes también le animan a formar una familia y tener hijos según los designios de Dios. Mientras Jesús estaba en el desierto, los discípulos le esperaban confusos, discutiendo si realmente es o no el Mesías, y escuchando las críticas de Judas hacia la volubilidad de Pedro. Cuando Jesús reaparece entre ellos, se muestra fuerte y confiado en haber encontrado su camino, dejando atrás el amor y la fraternidad para blandir un hacha en la necesaria guerra contra Satanás. Con fuerzas renovadas, toma conciencia como hijo de Dios y como Mesías y, junto a sus discípulos, comienza a realizar milagros, pero sin abandonar su humanidad y cercanía en otras tareas cotidianas. A pesar de su nueva confianza aún no es reconocido por su entorno, e incluso será despreciado en su localidad natal de Nazaret, donde es considerado como un loco o un mago. De camino hacia Jerusalén, Jesús realiza su mayor milagro, la resurrección de Lázaro sacándolo de la tumba días después de su muerte, un hecho realmente insólito que no hace más que apuntalar su condición de Mesías. $\mathrm{Al}$ entrar en la ciudad, Jesús se topa con una realidad muy alejada de la santidad o el recogimiento, y no se hace esperar su reacción violenta contra los mercaderes, tasadores, prostitutas, idólatras y matarifes que emponzoñan las calles. Jesús se pronuncia extremadamente crítico contra la ley religiosa o los privilegios de la casta sacerdotal, lo que provoca una tremenda reacción negativa en la ciudad que termina con su expulsión de ella. Los planes revolucionarios y violentos de los zelotes contra Roma chocan con los de Jesús, por lo que el rebelde Saulo decide matar a Lázaro para así eliminar la mayor y más patente prueba del supuesto Mesías. Los apóstoles de nuevo se muestran dubitativos y temerosos, pero finalmente se arman de valor para entrar en la ciudad y expulsar con firmeza a los 
mercaderes del Templo e incluso tomarlo por la fuerza, mientras Jesús espera una señal de Dios que le oriente sobre cómo proceder. De las manos de Jesús surgen entonces estigmas sangrantes, por lo que decide abandonar la rebelión violenta y aceptar su destino muriendo en la cruz para traer la salvación a la humanidad. Totalmente abatido, Jesús recuerda a Judas su advertencia de que, si se desviaba de la misión revolucionaria, lo mataría, pero el zelote no se siente capacitado y prefiere que sea Dios quien lo mate, por lo que Jesús asiente y solo le pide que facilite a Dios la tarea al delatarle a los guardias del Templo. En su última cena, acompañado de sus apóstoles, Magdalena, María y Marta, Jesús les informa sobre su inminente sacrificio redentor. En el huerto de Getsemaní se materializan los designios de Jesús cuando Judas aparece con los guardas del Templo para apresar al supuesto Mesías. En su cautiverio Jesús mantiene una interesante conversación con Pilatos, en la que el romano avisa sobre el peligro de sus ideas para acabar con Roma, para determinar finalmente que será castigado y crucificado. En el Gólgota, Jesús está dispuesto a comprobar por fin cuál era el plan de Dios para él, pero entonces un ángel lo baja de la cruz de manera inadvertida por los presentes y le explica que Dios ha comprendido que ya ha sufrido bastante y que puede salvarse de su sacrificio, confirmando que no era realmente el Mesías. Jesús emprende una vida normal y se casa con Magdalena, quien agradece a Dios que le haya devuelto a su amor. Jesús honra su matrimonio yaciendo con ella y la deja embarazada, pero Dios la mata con su hijo aún en su vientre, lo que provoca la ira de Jesús. El ángel le recuerda que Magdalena no es la única mujer en el mundo y anima entonces a Jesús a convivir con María, la hermana de Lázaro. Los años pasan y el ángel le sigue acompañando, aconsejándole en un momento dado que yazca con su cuñada Marta, para probar que en realidad solo hay una mujer en el mundo y no se trataría de adulterio. Ya anciano, avergonzado por sus errores y por haber buscado a Dios por derroteros equivocados, Jesús se encuentra con el zelote Saulo, convertido ahora en el apóstol predicador Pablo. Jesús le escucha indignado cómo relata su crucifixión y su resurrección a los tres días para redimir todos los pecados, ya que él realmente descendió de la cruz sin llegar a morir ni resucitar y ha llevado desde entonces una vida familiar normal. Pablo se justifica diciéndole que a él le da igual qué es lo que ocurrió realmente, y que ha creado una nueva verdad según las esperanzas y necesidades de la gente, infeliz y sufridora. Tiempo después, Jesús es visitado en su lecho de muerte por algunos de sus discípulos, pero la aparición de Judas causa una gran crispación, puesto que su mayor soporte en vida, el mayor valedor de su mesianismo, el que no quiso traicionarle matándolo, ahora le acusa de traidor, de haberse desviado por completo del camino en el momento final, de no haber completado su revolución, de no haberse sacrificado por la causa. Jesús se sorprende ante estas duras palabras de Judas pero reacciona advirtiendo que todo ha sido un sueño. El diablo lo sometió a 
una última tentación antes de morir en la cruz, personificándose en ese ángel que le ofreció todo lo que no pudo tener, todo lo que tuvo que sacrificar para plegarse al plan de Dios. Jesús se ve de nuevo en la cruz, comprendiendo con júbilo que ha superado ese paréntesis y que realmente es el Mesías:

¡Todo, todo, eran visiones provocadas por el Maligno! Sus discípulos estaban vivos y sanos, se habían lanzado a tierras y mares y pregonaban la Buena Nueva. Todo había sucedido como debía. ¡Bendito sea Dios!

Lanzó un grito de triunfo:

${ }_{-}$;Todo se ha consumado!

Y era como si dijera: «Todo comienza» (Kazantzakis, 2015: 722-723).

Al repasar el argumento de La última tentación salta a la vista que la novela en su conjunto es la culminación de esa búsqueda de Cristo por parte de Kazantzakis durante su vida y su carrera literaria. Superaba así las reflexiones puntuales o tangenciales sobre la figura de Jesús de Nazaret en obras precedentes para abordar una biografía en toda regla, pero a su peculiar manera y vertiendo en ella reflexiones personales de variada índole, desde religiosas o morales hasta filosóficas e incluso sociopolíticas. Una obra tan ilustre, tan extensa y tan densa ha dado lugar a múltiples interpretaciones que, en cualquier caso, vienen a conformar ciertas ideas generalmente aceptadas. Existen opiniones sobre un alegato a favor de la libertad del hombre ${ }^{6}$ y los múltiples obstáculos que debe superar, otras sobre la plasmación de la dicotomía humano-Dios o cuerpo-espíritu, e incluso otras sobre el conflicto interior del ser humano contra sí mismo. El propio autor mencionaba en el prólogo de la novela su intencionalidad y motivación fundamentales, que concuerdan tanto con su incesante búsqueda de Cristo como con esa lucha dialéctica entre lo humano y lo divino, entre lo corpóreo y lo espiritual:

La doble sustancia de Cristo ha sido siempre para mí un misterio profundo e insondable; el anhelo del hombre, tan humano, tan sobrehumano, de llegar hasta Dios -o más exactamente, de retornar a Dios e identificarse con Él-, esta nostalgia tan misteriosa y a la vez tan real, abría en mí heridas y grandes manantiales.

Desde mi juventud, mi angustia primera, la fuente de todas mis alegrías y de todos mis desasosiegos, ha sido ésta: la lucha incesante y despiadada entre el espíritu y la carne.

Había en mí fuerzas ancestrales y tenebrosas del Maligno, humanas y anteriores al hombre; había en mí fuerzas ancestrales y luminosas de Dios, humanas y anteriores al hombre, y mi alma era el campo de batalla donde estos dos ejércitos en conflicto se enfrentaban y se unían.

Una terrible angustia; amaba mi cuerpo y no quería que se perdiera; amaba mi alma y no quería que se degradara; luchaba por reconciliar estas

\footnotetext{
${ }^{6}$ Recordemos que en la tumba de Kazantzakis su epitafio es «Nada espero. Nada temo. Soy libre».
} 
dos fuerzas cósmicas antagónicas, por hacerlas sentir que no son enemigas sino colaboradoras, y porque gozaran de la armonía y al mismo tiempo gozar yo con ellas (Kazantzakis, 2015: 127).

Según el propio Kazantzakis, a lo largo de la novela Cristo pasa por cuatro estadios que se corresponden con cuatro partes del texto. El primero es el de «hijo del carpintero» (también «hijo de María»o simplemente «hombre joven»), sin llegar a usar todavía el nombre de Jesús; es la manera del cretense de definirlo inicialmente como un ser humano común que busca la felicidad, aunque se sume en dudas sobre su esencia y misión existenciales. Desde que el personaje es nombrado como Jesús, pasará por los tres últimos estadios, cuyas denominaciones se corresponden con términos cristológicos recogidos en la Biblia. El segundo estadio (y primero de nombre cristológico) es «hijo del hombre», a partir de su intervención frente a la lapidación de Magdalena, y viene caracterizado por la mansedumbre y los inicios de su predicación sobre el perdón. El tercero es «hijo de David», tras su retiro en el desierto, cuando apela a la fiereza blandiendo el hacha para batallar contra Satanás y se reconoce como Mesías. Por último, al final de la novela es nombrado como «hijo de Dios», cuando acepta su sacrificio. Estas cuatro denominaciones se corresponden con cuatro pasos en los que Kazantzakis escenifica el viaje ascendente desde lo terrenal a lo espiritual por el que abogó a lo largo de su carrera artística y su propia vida. Así, Cristo comienza como un humano común y poco a poco se va desprendiendo de su esencia terrenal, primero mediante el amor, y después mediante la violencia, hasta alcanzar la esencia espiritual como hijo de Dios encargado de la misión redentora encomendada por su padre. La última tentación es por tanto la culminación del uso de la figura de Cristo por parte de Kazantzakis como encarnación de ese viaje desde lo carnal a lo divino, como un modelo para el mundo moderno (entendido como los mediados del siglo Xx en los que escribió la novela) de su idea de lucha interior para superar los miedos que nos atenazan y vencer los obstáculos de la vida hasta alcanzar una pretendida perfección. Es decir, un ejemplo humano de lo que los humanos pueden llegar a alcanzar, entendiendo su esencia divina más como una consecución del viaje interior que como algo inherente a su figura.

La libertad con la que el escritor cretense abordó la figura de Cristo en La última tentación deja entrever diversas ideas heterodoxas a lo largo de sus páginas que, además, remiten a algunas de las fuentes apócrifas o heréticas de las que se nutrió en su proceso de producción. Por ejemplo, recoge los postulados de la herejía del adopcionismo (siglo II), que afirmaba que Jesús era una persona común que había sido elegida y adoptada por Dios para cumplir su misión, adquiriendo así su esencia divina; este planteamiento entronca perfectamente con el mencionado camino ascendente planteado por Kazantzakis desde el simple «hijo del carpintero» hasta convertirse en 
«hijo de Dios». Otra de las herejías recogidas en diversas ocasiones en la novela es la del gnosticismo (siglos I-IV), según la cual era posible desprenderse de la esencia material mediante un proceso de introspección individual sin mediación eclesiástica cuando se alcanzara el conocimiento secreto o «gnosis», identificado como el misterio de Dios ${ }^{7}$; esta contraposición entre materia y espíritu y este proceso sin necesidad de contar con la Iglesia son ideas no solo propugnadas de manera general por Kazantzakis en su obra, sino también de manera bastante profusa en esta novela, en la que se pueden rastrear dualismos como carne-Dios, luztinieblas o verdad-mentira. También es importante hacer referencia a la heterodoxia con la que Kazantzakis retrató en esta novela a otros dos personajes de gran entidad en ella: Judas y María Magdalena. En el caso del zelote, su consideración de personaje fuerte y principal responsable de la consecución de la misión redentora de Jesús, obviando el papel de traidor otorgado por el canon cristiano, puede provenir del Evangelio de Judas, un escrito apócrifo que Kazantzakis pudo conocer de manera indirecta ${ }^{8}$, así como de la novela histórica Las memorias de Judas (Ferdinando Petrucelli della Grattina, 1867), en la que el zelote era el único amigo de Jesús y lideraba un movimiento de liberación de Israel frente al poder romano. En el caso del personaje de Magdalena, su tratamiento heterodoxo en la novela entronca con la idea de la mujer y del sexo que tenía Kazantzakis, según la cual «tierra-materia-muerte-mujer se contraponen a cieloespíritu-superación de la muerte-varón» (Vilela Gallego, 2015: 97).

Evidentemente, el atrevimiento de Kazantzakis al marcar distancias frente a los dogmas establecidos del cristianismo y su mezcla de distintas teorías en torno a los hechos de la vida de Cristo dieron lugar a una recepción polémica de la novela. El escándalo fue generalizado en los ambientes oficiales de todas las Iglesias cristianas, tanto la católica como la ortodoxa y las protestantes, cuyos sectores más conservadores veían cómo el escritor cretense había creado una obra blasfema que recreaba los evangelios sin atender a la recta observación de las Escrituras. Poner de acuerdo a todas las iglesias cristianas en lo herético o blasfemo de la extrema humanidad de Jesús, de sus deseos sexuales, de la negativa de la Virgen María a que su hijo fuera el Mesías o de la heroicidad y rectitud de Judas fueron los detonantes principales de un escándalo generalizado a nivel mundial. Dentro de las fronteras griegas, el contexto de represión política tras la Guerra Civil (1946-1950) no era el más apropiado para una novela de semejante contenido, aunque la persecución de la misma y de su propia persona pudo ser vista desde la distancia de su exilio por

\footnotetext{
${ }^{7}$ Para mayor profundidad sobre el gnosticismo, puede consultarse a Riera Ginestar, 2017: 42-51.

8 «Casandsakis no podía conocer directamente el Evangelio apócrifo de Judas, porque en su tiempo el manuscrito no había salido a la luz. Pero sí lo conocía indirectamente a través de la herejía de los cainitas y por los escritos condenatorios de los Padres de la Iglesia» (Vilela Gallego, 2015: 81, nota 118).
} 
Kazantzakis ${ }^{9}$. De hecho, en 1954 hubo un intento de la Iglesia ortodoxa de Grecia de excomulgarlo, aunque sería frenada y desestimada por la mediación de la reina Federica de Grecia, quien tuvo en cuenta la amistad del escritor con su hijo, el príncipe Jorge de Grecia, y especialmente con la esposa de este, María Bonaparte, a quien precisamente estaba dedicada La última tentación. A nivel internacional, como ya se mencionó, la obra fue incluida en 1954 en el Index del Vaticano, mientras que en Estados Unidos, tras la publicación allí de la novela en 1960, la polémica petición de ciertos sectores protestantes de retirarla de las librerías no hizo más que generar un efecto rebote que aumentó sus ventas.

\section{Del SENTIMIENTO RELIGIOSO DE SCORSESE A LA NOVELA DE KAZANTZAKIS}

La prolífica y exitosa carrera del cineasta Martin Scorsese (Nueva York, 1942) es una sucesión de éxitos y fracasos, de apuestas personales y de encargos, de largometrajes de ficción y de documentales, e incluso algunas incursiones en el medio televisivo. Su reconocimiento a nivel mundial le ha llevado a ser considerado como uno de los profesionales del Cine más ilustres de las últimas décadas, y sus películas han cosechado premios en los más importantes certámenes de todo el planeta, como la Palma de Oro por Taxi Driver (1976) y el premio al Mejor director por iJo, qué noche! (After Hours, 1985), ambos en el Festival de Cannes, o el Oscar al Mejor Director por Infiltrados (The Departed, 2006).

Hay que retroceder hasta la infancia y la juventud del director neoyorquino para entender su relación con la religión. La familia de Scorsese, de raíces sicilianas, tuvo que abandonar el cómodo vecindario de Queens hacia 1950 por problemas económicos y establecerse en el barrio de Little Italy, al sur de Manhattan. En esa burbuja apegada al origen italiano de sus habitantes Scorsese adquiría y reforzaba su condición de italoamericano, un aspecto que ha llevado siempre consigo con orgullo y que por lógica tuvo posteriormente gran influencia en muchas de sus películas de ficción y documentales. Los problemas de salud de Martin, que tenía asma, le obligaron a estar bastante recluido en el apartamento familiar de Elizabeth Street, pero el Cine se convirtió en un fiel compañero y en una válvula de escape de su reclusión. Tras una adolescencia en la que recorre las a veces poco amables calles de Little Italy, finalmente decide a principios de la década de 1960 ingresar en la New York University para formarse como cineasta y unir definitivamente su destino a la gran pantalla.

\footnotetext{
${ }^{9}$ «[...] fue La última tentación -junto con algunos capítulos de El Capitán Mijalis- la que provocó la ira y la guerra de la Iglesia griega contra el escritor cretense, que fue acusado de impío y sacrílego por distorsionar el relato evangélico inspirado por Dios, mancillar la figura divina y humana del Señor y sus horas sobre la cruz de su Pasión y hacer mofa y escarnio - en ambas obras- de la enseñanza del dogma y la moral de la Iglesia ortodoxa» (Vilela Gallego, 2015: 68).
} 
Kazantzakis y Scorsese, dos autores frente a la controversia

En su infancia Scorsese había recibido una educación católica y desarrolló cierta vocación sacerdotal ${ }^{10}$, aunque se decantaría definitivamente por los estudios de Cine. Esta impronta religiosa ha influido en varias de sus producciones, en especial en los inicios de su carrera, con algunas cintas de cierto tono autobiográfico. Es el caso de su primer largometraje, ¿Quién llama a mi puerta? (Who's that knocking at my door, 1967), plagado de imágenes religiosas en interiores de domicilios de Little Italy, y que al final de su metraje tiene una escena dentro de la Vieja Catedral de San Patricio, a la cual acude el protagonista para buscar consejo en su confesor. En Malas calles (Mean Streets, 1973) aparecen las bulliciosas fiestas religiosas de San Gennaro en Little Italy al principio, y más adelante una escena igualmente ambientada en la Vieja Catedral de San Patricio, en la que otra vez el protagonista busca respuestas ${ }^{11}$. Aparte de otras referencias a aspectos puntuales de la religión católica a lo largo de la carrera de Scorsese y de la propia La última tentación de Cristo, cabe mencionar la entidad y el ascendente en la trama de Gangs of New York (2002) del personaje del sacerdote irlandés católico que aparece al inicio de la cinta y cuyo sacrificio puede considerarse como una aproximación a la Pasión de Cristo. El director neoyorquino ha llegado incluso a abordar de lleno la religión católica en Silencio (Silence, 2016), que trata las dificultades y la persecución de jesuitas portugueses en el Japón del siglo XVII y ahonda en el tema de la fe cristiana. Fuera del ámbito católico, pero también desde una perspectiva religiosa, debe ser mencionada Kundun (1997), que trata el budismo y la figura del decimocuarto Dalai Lama.

Pero, ¿cómo llegó Scorsese a adaptar La última tentación? El visionado de la película El Evangelio según San Mateo (Il Vangelo secondo Matteo, Pier Paolo Pasolini, 1964) habría causado un gran impacto en el por entonces estudiante de Cine en la NYU, animándole a pensar en una futura película que tratara la vida de Cristo, pero desde una perspectiva contemporánea y ambientada en Manhattan ${ }^{12}$. No es de extrañar la influencia del cine

${ }^{10}$ Según el propio Scorsese, de una manera algo egoísta, más que realmente vocacional (Ferreras, 2011: 111-112).

${ }^{11}$ Los protagonistas J.R. en ¿Quién llama a mi puerta? y Charlie en Malas calles están interpretados por Harvey Keitel, el primer actor fetiche de la carrera de Scorsese. Las escenas de ambas películas en la Vieja Catedral de San Patricio, muy similares entre sí, pueden ser consideradas como el homenaje del propio Scorsese al lugar que él frecuentaba para asistir a los servicios religiosos cuando vivía en Little Italy. Para más información sobre las escenas de contenido religioso de la película, vid. Ferreras, 2011: 112-117. Burnette-Bletsch (2019: 153-158) habla de las referencias religiosas en estas dos películas y añade otras en Taxi Driver (1976) y Toro Salvaje (Raging Bull, 1980).

12 «I had dreamed of filming the story of Christ in a contemporary settingdowntown New York, to be exact, where I grew up. When I saw Pasolini's The Gospel according to St. Matthew (1964), I felt that he had basically made that film fit the present: Gospel may have been set during the time of Jesus' life on earth, but it 
italiano en general o el de Pasolini en particular en un cineasta como Scorsese que, además de gran cinéfilo, es un auténtico enamorado de la cultura y, en particular, del cine del país de sus ancestros, algo de lo que dejaría muestra posteriormente en su largometraje documental Mi viaje a Italia / El cine italiano según Scorsese (Il mio viaggio in Italia, 1999). El director neoyorquino se vio conmovido por el extremo naturalismo del fresco cristológico de Pasolini, que había sido aplaudido por la crítica cristiana como una de las mejores plasmaciones cinematográficas de Cristo y «había obtenido el Gran Premio de la Crítica católica en Venecia, en 1964» (Ferro, 2008: 31), a pesar de la paradoja de estar realizada por un ateo confeso, una condición que puede relacionarse con la peculiar idea de la religión de Kazantzakis, aunque se aleja del catolicismo del cineasta itaolamericano.

Scorsese descubrió la novela de Kazantzakis durante el rodaje de El tren de Bertha (Boxcar Bertha. 1972), su segundo largometraje de ficción. Barbara Hershey, protagonista de esta película y «futura intérprete de María Magdalena, le pasó un ejemplar del libro, con vistas a que David Carradine, pareja de la actriz en esa época, pudiera hacer el papel de Jesús» (Fernández Valentí, 2008: 69). Scorsese siente que nunca podrá agradecerle lo suficiente a Hershey que le hubiera descubierto el libro ${ }^{13}$, ya que le resultó interesantísimo el enfoque de esta obra de ficción sobre la esencia de Jesús, reuniendo en sus páginas lo que se había ido debatiendo en diversos concilios durante los primeros mil años de existencia del Cristianismo: si Jesús fue totalmente humano o totalmente divino. Según la perspectiva oficial cristiana, Jesús posee esencia divina, pero para Kazantzakis partía de la humana y no accedía a su parte divina hasta el último momento, cuando acepta su sacrificio para la humanidad. Para Scorsese, Kazantzakis le ofrecía una nueva manera de acercarse a la figura de Cristo más allá de los Evangelios y había planteado la incógnita sobre dónde acababa el Jesús humano y empezaba el Cristo divino, y si el propio Jesús debía sentirse responsable de su esencia humana, al igual que lo había sido por la divina ${ }^{14}$. La elección de este texto con un Jesús tan humano

felt completely contemporary, from the casting to the point of view to the music» (Scorsese, 2005: 229).

13 «It was my friend Barbara Hershey who recommended that I read Nikos Kazantzakis's novel. She mentioned it for the first time in Arkansas, when we were shooting my film Boxcar Bertha, and then she brought it up again in Los Angeles. I'll never be able to thank her enough. I took my time reading the book. And as I always do whenever I get excited about a novel, I started to make notes. I realized, quickly, that I wanted to make a film based on The Last Temptation of Christ» (Scorsese, 2005: 229).

14 «When I read the Kazantzakis novel, with its magnificent language and its restlessly probing spirit -with that tone, at once so frank and so tender-I felt that I'd found another way of approaching Christ. Not to work from the Gospels, but from a novel that attempted to pinpoint the key conflict of his short life: Where did 
podría convertirse según el italoamericano en una cinta más accesible al público en general, además de servirle de manera personal «para replantear sus habituales obsesiones en torno a la culpa y la redención, para definitivamente exorcizar sus demonios personales en torno a la religión» (Monterde, 2000: 354). De hecho, según el propio Scorsese, había encontrado en la novela de Kazantzakis la conexión entre su presente y el que vivió Jesús, una manera de unión entre el Mesías y el mundo actual; su idea era que, de haberse manifestado en nuestro tiempo, estaría entre los oprimidos y los pobres, e intentaría llamar la atención sobre las miserias y las injusticias de nuestro mundo, lo cual generaría el rechazo e incluso la mofa de muchos, así como el propio sufrimiento de Jesús ${ }^{15}$. Esta idea de un Jesús moderno y cercano a quienes sufren entronca con esos sentimientos de culpa y redención mostrados por muchos de los personajes protagonistas de las películas de Scorsese.

\section{De la NOVEla a la PANTALla: La ÚlTIMA TENTACIÓN DE CRISTO}

A pesar de la atracción inmediata que la novela produjo en Scorsese, el proyecto de La última tentación de Cristo (The Last Temptation of Christ) no comenzó a tomar forma hasta unos diez años después de que Hershey se la mostrara por primera vez. Para empezar, en 1981 el cineasta neoyorquino escogió como intermediario entre Kazantzakis y su película al guionista Paul Schrader ${ }^{16}$. Y en 1983 la productora Paramount parecía decidida a financiarlo, en principio con un presupuesto de doce millones de dólares y un calendario de trabajo de tres meses. Pero cuando el productor Irwin Winkler solicitó aumentar el presupuesto y el tiempo de rodaje debido a las complicaciones lógicas por las localizaciones previstas en exteriores de Israel, la Paramount canceló el proyecto de la peor manera posible, solo una semana antes del comienzo del rodaje y con mucho trabajo de

his humanity end and his divinity begin? Kazantzakis understood something that few have ever understood as keenly in a work of art, be it a novel or a film. He understood that Jesus must have felt as much of an obligation toward his own humanity- an obligation to fulfill his life as a man, in the way we all feel it -as he did toward his divinity» (Scorsese, 2005: 229).

${ }^{15}$ «I had always thought that if Jesus had returned to walk among us, he would be living with the hookers, the junkies, the bag ladies. He would be trying to set the world aright, one soul at a time. And it's certain that many among us would be laughing at him. Scorning him. We would be upset that someone was calling attention to the misery around us, insisting that we not look away. And he would be suffering.

I found this longing to make a connection between our present and Jesus' present, to make us one with him and make him one with us, in Kazantzakis's novel» (Scorsese, 2005: 230).

${ }^{16}$ Schrader ya había asombrado al mundo cinematográfico con sus desgarradores textos para Scorsese en Taxi Driver (1976) y Toro Salvaje (Raging Bull, 1980) y con posterioridad trabajaría por última vez a sus órdenes en Al límite (Bringing out the dead, 1999). 
preproducción ya realizado, como decorados y vestuario ${ }^{17}$. Pero, además de las razones logísticas o económicas de la cancelación, la Paramount ya se había visto presionada por diversas organizaciones religiosas cristianas, que habían iniciado una campaña previa de desprestigio por el supuesto contenido blasfemo de la novela de Kazantzakis (Sotinel, 2010: 47; Monterde, 2000: 346). De hecho, las reticencias morales vinieron a sumarse a los condicionantes económicos de un poderoso exhibidor cinematográfico para terminar de enterrar el proyecto:

Pero de todas maneras, la chispa definitiva que hizo explotar el asunto fue la actitud de Salah Hassanein, un personaje medio egipcio y medio protestante [...], director de la cadena de salas cinematográficas United Artists Theatres en toda la zona de la costa Este; fue él quien avisó [...] de que no proyectaría el film de Scorsese bajo ningún concepto y que tampoco se emitiría por la $H B O$. Mucho más que las cartas de los moralistas, esa amenaza de boicot a la película [...] significaba el peligro de que se extendiese a otras áreas mucho más intolerantes todavía que la costa Este (Monterde, 2000: 347).

Si tenemos en cuenta que un porcentaje enorme de las producciones de Hollywood se apoyan en predicciones económicas, no es de extrañar la cancelación por parte de Paramount, pero Scorsese no abandonó la esperanza en poder realizarla. La posibilidad se planteó en el Festival de Cannes de 1986, donde su película iJo, qué noche! le valió ganar el premio al Mejor Director. Allí diversas personalidades políticas y de la industria cinematográfica le propusieron retomar el proyecto con rodaje en Egipto y un presupuesto contenido de cinco millones de dólares, pero el hecho de que uno de estos personajes fuera el ministro de cultura francés Jack Lang provocó el escándalo:

diversos grupos católicos de presión europeos protestaron ante Lang por su apoyo a un proyecto considerado «blasfemo», y más teniendo en cuenta que apenas un año antes medio mundo se había visto enfrascado en otra polémica de esta índole por culpa de un film francés, el famoso Yo te saludo, María (Je vous salue, Marie, 1984), del prestigioso Jean-Luc Godard, el cual hasta llegó a ser objeto de una condena papal. La gota que colmó el vaso fue la solemne protesta del cardenal Lustiger, arzobispo de París, contra el presidente de la república François Miterrand, alertándole de las consecuencias del uso de dinero público en un proyecto basado en un texto subversivo como la novela de Nikos Kazantzakis. Otros intentos de

\footnotetext{
${ }^{17}$ El vestuario fue aprovechado parcialmente para la película Rey David (King David, Bruce Beresford, 1985). Para el papel protagonista, rechazado por Robert De Niro al coincidirle con el rodaje de Érase una vez en América (Once upon a time in America, Sergio Leone, 1984), se habían barajado nombres como Christopher Walken, Eric Roberts y Aidan Quinn (Sotinel, 2010: 47; Fernández Valentí, 2008: 70; Monterde, 2000: 345).
} 
Kazantzakis y Scorsese, dos autores frente a la controversia

poner en pie La última tentación de Cristo en Rusia o Grecia también fracasaron (Fernández Valentí, 2008: 74).

Después de haberse embarcado en un largometraje de encargo, El color del dinero (The Color of Money, 1986), a principios de 1987 Scorsese vuelve a la carga con La última tentación de Cristo y, con la mediación de su nuevo agente Michael Ovitz, consigue que sea viable a través de la productora Universal, si bien con unas condiciones mucho más modestas que las inicialmente propuestas en 1983 a Paramount: la mitad de presupuesto, calendario de dos meses, rodaje en Marruecos y papel protagonista para Willem Dafoe. En cualquier caso, Scorsese, después de todos los avatares sufridos durante 4 años, se sumerge por fin en su soñada adaptación de la novela de Kazantzakis, que comienza su rodaje en septiembre de 1987 (Sotinel, 2010: 51; Fernández Valentí, 2008: 82) en diversas localizaciones marroquíes, como Oumnast, Mequinez, el sitio arqueológico de Volubilis, las colinas de Azron y el valle del Itlo en la cordillera del Atlas (Monterde, 2000: 350). La elección de estas localizaciones reales podría ser considerada una influencia en Scorsese de las varias ocasiones en las que Pasolini ambientó sus películas con gran naturalismo en ruinas o ilustres monumentos ${ }^{18}$. Al igual que Pasolini conseguía aportar un extraño naturalismo rodando en lugares ya decadentes y despoblados para representar el pasado, Scorsese creó una puesta en escena muy acertada en cuanto a sobriedad y naturalidad, consiguiendo ser muy convincente al recrear la Palestina de tiempos de Cristo de una forma alejada de otros retratos bíblicos más idealizados. De hecho, una de las grandes peculiaridades de la película es que rezuma un sabor mucho más árabe o beréber que judío, algo que va más allá de paisajes y localizaciones para dejarse ver también en los figurantes y sus ropajes, e incluso en algunas ceremonias sociales o religiosas que aparecen a lo largo del metraje, como la escena de las bodas de Caná. El contenido presupuesto no fue obstáculo para un equipo de rodaje henchido de pasión $\mathrm{y}$ fe en el mismo, lo que derivó en todo tipo de sacrificios, como movilizar a los 135 figurantes disponibles para todas las escenas, usar a cinco especialistas como todos los soldados romanos o que Barbara Hershey se hiciera y repasara personalmente los tatuajes que mostraba su personaje de Magdalena (Fernández Valentí, 2008: 82). Las localizaciones, los decorados, el vestuario, las interpretaciones, los figurantes... El conjunto es extremadamente naturalista, y solo hay algún momento puntual de

\footnotetext{
18 Aparte de la mencionada El Evangelio según San Mateo (1964), rodada en el conjunto arqueológico de Matera, pueden citarse localizaciones en sitios arqueológicos o conocidos monumentos en Edipo rey (Edipo re, 1967), Medea (1969), El Decamerón (Il Decameron, 1971), Los cuentos de Canterbury (I racconti di Canterbury, 1972) o Las mil y una noches (Il fiore delle mille e una notte, 1974).
} 
carácter onírico-fantástico que requirió de efectos visuales, como el león que se le aparece a Jesús en el retiro del desierto ${ }^{19}$.

En relación con la puesta en escena hay que mencionar la excepcional fotografía de Michael Ballhaus (1935-2017), veterano de la televisión y el cine alemán que posteriormente se afincó en Estados Unidos ${ }^{20}$. Ballhaus marca grandes contrastes entre unos exteriores muy luminosos y unos interiores y escenas nocturnas que cuentan con una iluminación artificial muy forzada y efectista. La cámara es muy dinámica en sus movimientos, aportando por ejemplo, como en otras películas de Scorsese, una de sus reconocibles marcas de autor, el uso de la cámara lenta para añadir intensidad y emoción. Además, aparecen algunos zooms rápidos para acercarse a la cara y los gestos de Jesús; también algunos movimientos de cámara que dan lugar a planos de gran belleza, como el movimiento de vertical a horizontal en la crucifixión; y, en definitiva, planos realmente impresionantes, algunos de ellos con enorme emotividad, como al final del metraje cuando Magdalena lava las heridas de Jesús, o cuando este, ya anciano, yace en un tálamo y el plano rememora la célebre obra pictórica del Cristo muerto de Mantegna (con los pies en primer plano). Por cierto, el abultado metraje de la cinta (163 minutos) no llega a hacerse pesado y mantiene ritmo en todo momento, algo que sin duda hay que agradecer en gran medida a la novela de Kazantzakis, pero también a la maestría en el montaje de la ilustre editora de Thelma Schoonmaker, fiel compañera de Scorsese en su carrera ${ }^{21}$.

En el reparto hay tres nombres que destacan por encima de los demás y cuyos papeles tienen mayor peso en la narración. Para empezar, Willem Dafoe, un actor que por entonces estaba comenzando una carrera que con el tiempo le ha consolidado como un nombre ilustre del cine mundial, fue el recurso final de Scorsese para interpretar a $\mathrm{Cristo}^{22}$; su poderosa

\footnotetext{
${ }^{19}$ Los efectos corrieron a cargo de Industrial Light \& Magic, la empresa creada por George Lucas para desarrollar los efectos de la saga original de Star Wars, y que después serviría a innumerables películas (Fernández Valentí, 2008: 87).

${ }^{20}$ Su colaboración con Scorsese comienza en iJo, qué noche! (1985) y se desarrolla después en otros títulos del italoamericano.

${ }^{21}$ Schoonmaker comenzó a trabajar con Scorsese en su ópera prima, ¿Quién llama a mi puerta?, y ha mantenido esta colaboración en casi toda su carrera en cine y televisión, con cerca de una treintena de títulos del italoamericano editados por ella. Su trabajo le ha granjeado un reconocimiento que se ha traducido hasta ahora, por ejemplo, en la consecución de tres premios Oscar al Mejor Montaje, por Toro Salvaje (Raging Bull, 1980), El aviador (The Aviator, 2004) e Infiltrados (The Departed, 2006).

22 Dafoe sustituía como protagonista al preferido de Scorsese, el por entonces todavía prometedor Aidan Quinn, que declinó al coincidirle con el rodaje de Crusoe (C. Deschanel, 1988). Sus papeles de traficante de droga en Vivir y morir en Los Ángeles (To Live and Die in L.A., William Friedkin, 1985) y del sargento Elias en Platoon (Oliver Stone, 1986) impresionaron a Scorsese y precipitaron su decisión (Monterde, 2000: 351; Sotinel, 2010: 51).
} 
interpretación reúne un espectacular despliegue de diferentes gestos, sentimientos y estados de ánimo realizados con maestría. Junto a él, otro actor muy prolífico y de innegable calidad, Harvey Keitel, descubierto precisamente por Scorsese en su ópera prima y convertido en su primer actor fetiche, presente en la mayoría de sus primeras películas como director; su papel de Judas está lleno de rabia y ansiedad. El tercer nombre destacado es el de Barbara Hershey en su segundo y último papel con Scorsese, muchos años después de haber protagonizado El tren de Bertha, pero permaneciendo lógicamente en el casting cuando el director abordó finalmente la producción, lo cual no es de extrañar al haber sido ella quien le mostró la novela de Kazantzakis; su sensual interpretación de María Magdalena, rebosante de potentes sentimientos contrapuestos llevados con solvencia y credibilidad, fue uno de los elementos más polémicos de la película. Aparte de estos tres personajes principales, cabe citar también a Verna Bloom (1938-2019) ${ }^{23}$ como María, madre de Jesús; al ya veterano cineasta Irvin Kershner (1923-2010) ${ }^{24}$, que debutaba como actor en esta película con su pequeño papel de Zebedeo; al prolífico actor Harry Dean Stanton (1926-2017), con su papel de Saulo, convertido en Pablo al final de la cinta; a David Bowie (1947-2016) en una de sus apariciones en la gran pantalla, en esta ocasión con el fugaz papel de Poncio Pilatos ${ }^{25}$ y al propio Scorsese, que realizaba uno de sus típicos cameos como el sacerdote Elías (sin que se le viera el rostro) en un flashback narrado por Jesús.

Otra de las grandes bazas de la película es la excelente banda sonora compuesta por Peter Gabriel para la ocasión, uniendo tradición y modernidad para conseguir crear una atmósfera de otra época y casi de otra realidad ${ }^{26}$. La música tiene un potente acento africano y árabe, con predominancia de instrumentos de percusión y de cuerda, acompañados perfectamente por algunos coros y las voces de ilustres cantantes como el senegalés Youssou N'Dour o la del pakistaní Nusrat Fateh Ali Khan. La propia banda sonora sería desarrollada durante meses tras el estreno de la película y finalmente editada en 1989 con el título de Passion, convirtiéndose en la segunda banda sonora de Gabriel y su octavo disco en solitario. De hecho, su edición constituye un hito en lo que conocemos como world music o músicas del mundo, ya que consiguió que una música y

${ }^{23}$ Quien ya apareció en un pequeño papel a las órdenes de Scorsese en iJo, qué noche! (1985).

${ }^{24}$ Cuyo título más conocido como director es El imperio contraataca (Star Wars: Episode V - The Empire Strikes Back, 1980).

${ }^{25}$ Bowie sustituyó en el papel a Sting, que no pudo rodar por problemas de agenda personal. En cualquier caso, Bowie rodó todos sus planos en un solo día (Monterde, 2000: 351).

${ }^{26}$ «La música orientalizante de Peter Gabriel ayuda a construir toda la variedad de atmósferas y ambientes con una gama que va de lo fúnebre a lo dionisíaco y de lo terrenal a lo visionario» (Solomon, 2002: 211). 
unos artistas hasta entonces casi desconocidos para el público occidental fueran abriéndose paso a nivel planetario más allá de sus lugares de origen.

Con La última tentación de Cristo, Scorsese marcaba un nuevo hito en la prolífica, variada y constante tradición de producciones religiosas que han representado a Cristo:

La práctica totalidad se ha movido entre la devoción sincera y la gran superproducción, entre directores que querían manifestar su fe y productores que aplicaban a esas historias un estricto sentido comercial. Lo cierto es que la figura de Jesús atrajo desde muy pronto a los pioneros del cine, como Lumière y Méliès, y ha seguido fascinando a los cineastas más diversos a lo largo de los años (Méndiz, 2009: 42).

Si en los primeros años del Cine, durante la etapa silente, diversas producciones crearon los primeros estereotipos de la representación cinematográfica de $\mathrm{Cristo}^{27}$, a mediados del siglo Xx encontramos las que podrían considerarse como películas clásicas, que formalizan definitivamente la imagen canónica del Cristo cinematográfico, caracterizada por gran solemnidad y una imagen idealizada, mostrándolo incluso en algunas ocasiones de manera indirecta o fugaz ${ }^{28}$. Pero la película de Scorsese es más deudora de una serie de producciones desde mediados de la década de 1960 que mostraron un marcado carácter personal (en ocasiones heterodoxo) y en las que se empezó a incidir en una imagen más humana de Cristo. Como ya se ha referido, es clara la influencia en $L a$ última tentación de Cristo de El evangelio según san Mateo de Pasolini, en especial la naturalidad y humanidad del personaje de Cristo encarnado por el español Enrique Irazoqui. Un cinéfilo empedernido como Scorsese pudo también tener en cuenta la libre (y polémica) aproximación a la figura de Cristo a través de diversas herejías de los inicios del cristianismo en La Vía Láctea (La Voie lactée, Luis Buñuel, 1969), así como el gran impacto del

${ }^{27}$ Entre otras, La Vie et la Passion de Jésus-Christ (Georges Hatot y Louis Lumière, 1897), Del pesebre a la cruz (From the Manger to the Cross, Sidney Olcott, 1912), Christus (Giulio Antamoro, 1916), Intolerance (David Wark Griffith, 1916), Páginas del Libro de Satán (Blade af Satans Bog, Carl Theodor Dreyer, 1920), Ben-Hur (BenHur: a tale of the Christ, Fred Niblo, 1925) o El rey de reyes (The King of Kings, Cecil B. DeMille, 1927).

${ }^{28}$ Pueden destacarse Gólgota (Golgotha, Julien Duvivier, 1935), El mártir del calvario (Miguel Morayta, 1952), La túnica sagrada (The Robe, Henry Koster, 1953), El beso de Judas (Rafael Gil, 1954), Ben-Hur (William Wyler, 1959), Rey de Reyes (King of Kings, Nicholas Ray, 1961) o La historia más grande jamás contada (The Greatest Story ever told, George Stevens, 1965). A pesar de ser más tardía y televisiva, otra de las obras audiovisuales canónicas en cuanto a la imagen idealizada de Cristo es la miniserie Jesús de Nazaret (Jesus of Nazareth / Gesú di Nazareth, Franco Zeffirelli, 1977); de hecho, la imagen del actor Robert Powell como Cristo sirvió de modelo desde entonces para multitud de representaciones sacras de la Iglesia católica (por ejemplo, estampas impresas). 
musical Jesucristo Superstar (Jesus Christ Superstar, Norman Jewison, 1973) ${ }^{29}$. Con posterioridad a su estreno, el retrato humano y natural de la figura de Jesús en La última tentación de Cristo ha podido ejercer cierta influencia en producciones cinematográficas de contenido cristológico del nuevo milenio $^{30}$, que han venido a sumarse al renacimiento del interés en películas ambientadas en la Antigüedad desatado a partir del éxito de Gladiator (Ridley Scott, 2000) ${ }^{31}$.

Antes de que su película fuera estrenada, Scorsese esperaba por lógica (y por desgracia) cierta oposición por tratar un tema religioso y ciertas ideas sobre Dios. Pero la llegada a pantallas de todo el mundo a partir del verano de 1988 dio lugar a una ola de rechazo y de protestas por su contenido herético o blasfemo que desbordó las expectativas iniciales. La polémica generada tenía que ver no solo con la visión de Jesús que tenía Kazantzakis, sino también con el guion de Schrader, con el conjunto de la película (sobre todo algunos pasajes puntuales) y con la interpretación de Willem Dafoe. Hubo quienes dijeron que la película era más sacrílega aún que el libro de Kazantzakis, aunque en realidad la novela sea más larga y pormenorizada. Las reacciones negativas no se hicieron esperar:

Hubo de todo: desde públicas condenas de la película por parte de relevantes figuras religiosas como el Papa Juan Pablo II o la Madre Teresa de Calcuta, hasta pintorescas anécdotas como la protagonizada por Bill Bright, un predicador evangélico presidente de la Cruzada por Cristo (sic) que ofreció pagar 10 millones a Universal a cambio de todas las copias y negativos del film para luego destruirlos (Fernández Valentí, 2008: 83).

Esta última reacción provocó el efecto contrario y aumentó la popularidad de la cinta en Estados Unidos, ya que la productora Universal

\footnotetext{
${ }^{29}$ Años antes del estreno de La última tentación de Cristo, dos comedias bastante conocidas se aproximaron a la figura de Cristo, aunque es difícil discernir si ejercieron alguna influencia en la cinta de Scorsese. Una es La vida de Brian (Life of Brian, Terry Jones, 1979), parodia de argumento paralelo a la Pasión creada por el grupo humorístico británico Monty Python, que causó gran revuelo en diversos sectores religiosos (y no únicamente cristianos), a pesar de tratar con respeto a Jesús, mientras se centraba en su vecino de pesebre Brian Cohen, encarnado por Graham Chapman. La otra es la parodia histórica La loca historia del Mundo (History of the World, Part I, Mel Brooks, 1981), en la que John Hurt interpretaba a Cristo en una Última Cena bastante peculiar.

${ }^{30}$ Hasta la fecha pueden citarse La Pasión de Cristo (The Passion of the Christ, Mel Gibson, 2004), Últimos días en el desierto (Last Days in the Desert, Rodrigo García, 2015), Ben-Hur (Timur Bekmambetov, 2016), Resucitado (Risen, Kevin Reynolds, 2016) o María Magdalena (Mary Magdalene, Garth Davis, 2018). Otro ejemplo mucho más modesto (y con escaso éxito de público y crítica) es la película española El Discipulo (The Disciple, Emilio Ruiz Barrachina, 2010), en la que un Jesús heterodoxo es despojado de sus aspectos divinos, pero desde una «ideología anticristiana» y con «falsas pretensiones historicistas» (Contreras Guerrero, 2012).

${ }^{31}$ Para conocer más sobre el "efecto Gladiator", véase Aguado Cantabrana, 2020.
} 
utilizó la prensa para denunciar la oferta de Bright como una coerción de la libertad $^{32}$. Más allá de las fronteras estadounidenses hubo reacciones a la película de lo más variopinto, incluyendo fuertes rechazos.

La puesta de largo internacional tuvo lugar en el Festival de Venecia de 1988, con un pase fuera de competición el 7 de septiembre que provocó protestas previas de colectivos religiosos y tuvo que pasar por la justicia antes de decidirse finalmente, llegando incluso a pasar por los tribunales la decisión de su proyección (Lindlof, 2008: 286-287). Pero quizá el mayor rechazo que sufrió la película en el Festival vino por parte de Franco $Z_{\text {Zeffirelli }}^{33}$, quien «retiró su película El joven Toscanini del Festival de Venecia porque se había incluido en su programa la película "totalmente trastornada” de Scorsese» (Solomon, 2002: 210), y llegó a verter duras e injustas acusaciones antisemitas contra la película, sorprendentes si tenemos en cuenta que Scorsese era, como ya se ha comentado, católico practicante (Lindlof, 2008: 286-287). En cualquier caso, la proyección pudo llevarse a cabo sin muchas complicaciones con la presencia de Scorsese y parte del equipo y, de hecho, hubo que realizar pases complementarios a lo largo del festival para acomodar a todos los interesados, mientras que las exhibiciones comerciales en Italia dejaron un resultado muy exitoso (Lindlof, 2008: 287-288).

El Reino Unido había sido el primer país europeo con proyecciones comerciales de la película de Scorsese, y las noticias sobre la controversia al otro lado del Atlántico provocaron reacciones dispares, desde el rechazo y el boicot (prohibición de los carteles de la película en el metro londinense, amenazas de bomba y personales a los distribuidores) a editoriales en prensa censurando la intromisión religiosa en la exhibición y, finalmente, un resultado muy positivo en taquilla (Lindlof, 2008: 289291). En Francia las cosas fueron más exageradas, y el rechazo proveniente de diversos sectores religiosos se materializó en una ola de intolerancia con resultados trágicos:

su estreno comercial tuvo lugar en París el 28 de agosto. Lanzada en 17 salas, el 19 de septiembre solo permanecía en dos salas, no a causa del fracaso comercial, sino por el miedo de los exhibidores ante la extraordinariamente virulenta campaña también desatada en Francia, sobre todo a partir de la condena pública pronunciada el 3 de septiembre por parte del arzobispo de París, monseñor Lustiger, y del presidente de la Conferencia Episcopal, monseñor Decourtray, que por supuesto no habían visto la película [...]. Las consecuencias llegaron cuando el 22 de ese mismo mes era incendiado uno de los dos cines resistentes, el SaintMichel, causando trece heridos, o con la bomba incendiaria colocada en un cine de Besançon, además de la violencia desencadenada en lugares como

\footnotetext{
32 «La respuesta de Universal Pictures fue la publicación en la prensa de una página entera de publicidad del film en la que se decía que la libertad de pensamiento no estaba a la venta» (Vilela Gallego, 2015: 70).

${ }^{33}$ Director de la miniserie televisiva de 1977 Jesús de Nazaret (citada en nota 28).
} 
Kazantzakis y Scorsese, dos autores frente a la controversia

Lyon, Laval, Rennes, Avignon, Angers, Poitiers, Nantes, Lille, etc. Finalmente, una granada lacrimógena lanzada en el Miramar-Montparnasse provocaba la muerte por asfixia de un espectador (Monterde, 2000: $353)^{34}$.

A España llegó en octubre de 1988 y las protestas previas no se convirtieron en graves incidentes en el momento del estreno, pero sí hubo manifestaciones religiosas y amenazas ${ }^{35}$. A pesar de las protestas, el resultado final de taquilla en las salas españolas fue más que satisfactorio y cercano al éxito de la película en Italia ${ }^{36}$.

En cualquier caso, más allá de todas estas reacciones negativas, no hay que dejar de mencionar que, a pesar del ajustado resultado comercial, con pocas ganancias frente a su inversión, la película causó un gran impacto en todo el mundo y el nombre de Scorsese recibió un gran impulso, sin olvidar que llegaría a ser nominado en la categoría de Mejor Director para los Premios Oscar celebrados en 1989:

Poco importa que, al final, La última tentación de Cristo no fuera un gran triunfo taquillero, primero porque era muy difícil que lo fuera, y segundo porque aún sin serlo logró convertirse en la producción cinematográfica más comentada de la temporada. [...] acabó siendo más un triunfo personal que económico, pero benefició enormemente a Scorsese, quien vio aumentar su prestigio y empezaron a lloverle ofertas laborales (Fernández Valentí, 2008: 88).

En el resto de Europa y en los demás continentes las reacciones fueron muy dispares, desde estrenos sin incidentes a problemas con la calificación, pasando por la retirada de cartelera, las especificaciones en cartelería y salas de proyección, e incluso la prohibición; de hecho, habría que esperar muchos años para su estreno en países como Sudáfrica (1998) o Chile (2001) (Lindlof, 2008: 295-299).

\section{ENTRE LA NOVELA Y LA PANTALLA: LA ADAPTACIÓN}

Scorsese se convirtió en el tercer cineasta que adaptaba a la gran pantalla una novela de Nikos Kazantzakis, después de que Jules Dassin

${ }^{34}$ Para más información sobre la polémica en Francia, véase Lindlof (2008: 291295).

35 «La película La última tentación de Cristo, de Martin Scorsese, que desde su rodaje y estreno está provocando la protesta y brotes de violencia, se presentó ayer en varias capitales españolas sin que, al cierre de esta edición, se hubieran producido incidentes de consideración. Grupos reducidos de personas se han manifestado con rezos, produciéndose pintadas y amenazas. Algunos empresarios de las salas contrataron guardas jurados y la policía mantuvo una especial vigilancia» (Anónimo, 1988).

${ }^{36}$ «Of all the countries that allowed the picture to be shown, only Spain -another solidly Roman Catholic mantion- had as large a box-office result» (Lindlof, 2008: 288). 
hiciera lo propio con Cristo de nuevo crucificado en su película El que debe morir (Celui qui doit mourir, 1957) ${ }^{37}$ y Michael Cacoyannis a partir de Vida y hechos de Alexis Sorbás con su Zorba el Griego (Zorba the Greek, 1964) ${ }^{38}$. Con posterioridad, Yannis Smaragdís ha continuado la senda con su película Kazantzakis (2017) partiendo de Informe al Greco ${ }^{39}$.

La película de Scorsese intentó seguir las líneas generales del texto de Kazantzakis, ya de por sí largo y de gran densidad narrativa. Paul Schrader consiguió que las 600 páginas de la novela se quedaran reducidas a 90 de guion en solo cuatro meses, y posteriormente fue asistido por el crítico y guionista Jay $\operatorname{Cocks}^{40}$ durante otros ocho meses para revisarlo hasta conseguir una versión definitiva (Monterde, 2000: 345). A pesar de tener que obviar o resumir algunos pasajes del texto original y de la mencionada maestría de Thelma Schoonmaker en la sala de montaje, por fuerza el metraje debió ser extenso, por encima de las dos horas y media ${ }^{41}$.

Antes de los títulos de crédito iniciales, ya hay dos mensajes directos sobre la adaptación de la obra de Kazantzakis. El primero es la reproducción parcial del inicio del prólogo de la novela, obra del propio Kazantzakis, mediante un texto en movimiento:

The dual substance of Christ - the yearning, so human, so superhuman, of man to attain God... has always been a deep inscrutable mystery to me. My principle anguish and source of all my joys and sorrows from my youth onward has been the incessant, merciless battle between the spirit and the flesh... and my soul is the arena where these two armies have clashed and met $^{42}$.

El segundo, visible cuando desaparece el texto anterior, es una advertencia sobre esa fuente en la que se basa el guion: «This film is not based upon the Gospels but upon this fictional exploration of the eternal

\footnotetext{
${ }^{37}$ Véase en este mismo monográfico el artículo de López Jimeno.

${ }^{38}$ Véase en este mismo monográfico el artículo de Valverde García.

${ }^{39}$ Véase en este mismo monográfico el artículo de González Vaquerizo.

${ }^{40}$ Con posterioridad, Cocks realizaría a las órdenes de Scorsese los guiones de $L a$ edad de la inocencia (The Age of Innocence, 1993), Gangs of New York (2002) y, en coescritura con el cineasta neoyorquino, Silencio (Silence, 2016).

${ }^{41}$ De haber sido más cercanos a la densidad de la novela, la duración habría sido escandalosamente larga. En cualquier caso, no olvidemos que las películas sobre la figura de Jesús de Nazaret tampoco han sido precisamente cortas por norma general.

${ }_{42}$ «La doble sustancia de Cristo, el anhelo del hombre, tan humano, tan sobrehumano, de llegar hasta Dios... ha sido siempre para mí un misterio profundo e insondable. Desde mi juventud, mi angustia primera, la fuente de todas mis alegrías y de todos mis desasosiegos, ha sido la lucha incesante y despiadada entre el espíritu y la carne... y mi alma era el campo de batalla donde estos dos ejércitos en conflicto se enfrentaban y se unían» (tomado de la película, traducción según Kazantzakis, 2015: 127).
} 
Kazantzakis y Scorsese, dos autores frente a la controversia

spiritual conflict» ${ }^{43}$. Ninguno de estos dos textos se antoja gratuito, sino que ambos parecen necesarias justificaciones de la película, relacionadas directamente con la polémica previa.

La apuesta personal de Scorsese $^{44}$ y de Schrader por expresar de manera libre y valiente sus reflexiones religiosas y sus dudas frente al discurso oficial de la Iglesia $^{45}$ encontró acomodo en la novela de Kazantzakis y en su adaptación:

dentro de su carrera, supone el punto culminante de sus inquietudes de índole religioso, respecto a las cuales lleva a cabo una especie de ajuste de cuentas prácticamente definitivo, contando para ello con la inestimable colaboración en el guión de Paul Schrader, otro cineasta, recordemos, con el que coincide en gran medida en su obsesión por los conflictos morales y éticos de sus personajes. No es de extrañar que se sintieran muy identificados tanto con la trama como sobre todo el espíritu redentor y purificador que anida en el seno de la novela original de Kazantzakis, la cual adaptan con bastante fidelidad, probablemente porque ambos se reconocen en ella (Fernández Valentí, 2008: 85).

Ambos demostraban así que, para expresar su visión cristológica libre, no tenían por qué basar el argumento directamente en los Evangelios, sino aprovechar la peculiar parábola evangélica contenida en la novela de Kazantzakis:

Scorsese y Schrader no pretendían convertir la película en un púlpito desde el cual lanzar una airada prédica sobre la figura de Cristo, sino usar una historia sobradamente conocida que, por su carácter de icono de la cultura universal, era perfecta para plasmar en ella sus obsesiones, con la misma libertad con que lo hizo Pasolini desde una heterodoxia de la cual Scorsese bebe abundantemente (Fernández Valentí, 2008: 86).

La poderosa interpretación de Willem Dafoe como Jesús de Nazaret capta en gran medida la dualidad y el camino ascendente del personaje que proponía Kazantzakis en la novela. Su faceta humana y terrenal toma forma a través de sus imperfecciones, dudas y miedos, de la constatación de que no es infalible y de las dificultades para reconocer su propia misión e incluso que le sigan. En su camino hacia la divinidad encontrará obstáculos tanto terrenales como espirituales, y poco a poco irá adquiriendo un halo

${ }^{43}$ «Esta película no se basa en los Evangelios, sino en esta exploración ficticia del eterno conflicto espiritual» (tomado de la película, traducción propia).

${ }^{44}$ Monterde afirma que se trata del «film que atañe más personalmente a Scorsese de cuantos ha rodado, lo cual no significa de forma necesaria que deba ser el mejor de entre los suyos» (2000: 359).

${ }^{45}$ La última tentación de Cristo «demuestra gran valentía y honradez al plantearse una serie de preguntas y objeciones perfectamente lógicas en cualquier persona de formación cristiana que no vaya por la vida con las cómodas anteojeras de la infalibilidad papal» (España, 2009: 410). 
menos físico, más etéreo. Si la mayoría de producciones sobre la figura de Cristo anteriores a la de Scorsese lo habían tratado como un personaje que permanecía en un espacio sagrado solo visible desde un punto de vista externo, el director neoyorquino conseguía superar este tabú mediante la adaptación de la novela de Kazantzakis, aportando al espectador acceso directo a los pensamientos y emociones de Jesús, mostrándolo como un personaje completo, con sus sufrimientos, sus dudas y su evolución a lo largo del metraje ${ }^{46}$. Scorsese quería explorar la plena humanidad de Jesús mostrando sus dificultades para resistir a la tentación, así como las dudas sobre su verdadera identidad y su propósito, y para ello la novela de Kazantzakis le iba como anillo al dedo ${ }^{47}$.

El otro personaje capital es Judas, interpretado en la película de manera rabiosa y ansiosa por Harvey Keitel, cercano en emociones al personaje de la novela, aunque evidentemente con mucho menor desarrollo. El temible zelote es enviado a matar a Jesús, pero las dudas ante el sufrimiento del carpintero le llevan a perdonarlo y decidir seguirlo de cerca para comprobar si realmente es el ansiado Mesías que debía liberar a los judíos de la dominación romana. Judas irá poco a poco descubriendo el poder que va creciendo y mutando en Jesús, pasando desde el rechazo inicial (de raíz política sobre todo) a tomarlo como maestro e incluso convertirse en su apoyo más cercano y, en definitiva, en el agente más importante de la Pasión ${ }^{48}$. La evolución de Judas a lo largo del relato va casi paralela a la de Jesús, pero ambos definen dos líneas que se van acercando y alejando en la narración, con momentos de gran entendimiento y otros de total incomprensión. El retrato de este personaje se aleja de la tradición cristiana canónica y recibe influencia del texto apócrifo del Evangelio de Judas, que precisamente lo considera como el discípulo más importante y allegado a Jesús, al que solo traicionaría siguiendo el designio expreso de su maestro. El personaje también se ve influido de manera directa por el propio pensamiento de Kazantzakis, que sí creía en Cristo, pero no en la institución de la Iglesia; por ello en la

\footnotetext{
${ }^{46}$ «Prior films had treated the Christ like a sacred object that could be seen and experienced only from an external point of view, while his consciousness remained an inaccessible sacred space. Scorsese violated this taboo by giving viewers direct access to Jesus' thoughts and emotions. The result is a depiction of the incarnate Christ as a fully round character who struggles, doubts, and evolves over the course of the film» (Burnette-Bletsch, 2019: 153).

${ }^{47}$ «For such a Jesus, ordinary human temptations would present no challenge at all. Scorsese wanted to explore the Savior's full humanity by showing him struggle to resist temptation and experience uncertainty over his identity and purpose. This is what drew him to Kazantzakis's novel as source material » (Burnette-Bletsch, 2019: 158).

${ }^{48}$ «Lejos de cualquier identidad traicionera, Judas será el garante del itinerario redentor de Cristo, cuando menos en su dimensión religiosa ya que no en la política, en la liberación del pueblo judío que sería su máximo anhelo» (Monterde, 2000: 366).
} 
novela Judas se enfrenta a los discípulos de Jesús de manera vehemente, incluso mofándose de ellos, presentándolos como personas dubitativas y timoratas, y consiguiendo así de manera indirecta atacar a uno de los cimientos de la institución eclesiástica. Si hablamos de personajes poco canónicos, hay que detenerse en el de Magdalena, que tiene mayor entidad y presencia en el libro, pero también tiene su importancia en la producción de Scorsese. Si en la novela se considera que es una prima de Jesús $^{49}$, en la película no hace falta más que mencionar un supuesto romance de juventud, del cual ella habría salido muy dolida por haber sido rechazada y ver que Jesús escogía seguir los designios divinos. La interpretación del personaje por Barbara Hershey cerraba el círculo en torno a la relación de Scorsese con Kazantzakis, y su polémico papel está correctamente dibujado respecto a la idea de carnalidad y sexo creada por el escritor cretense (Vilela Gallego, 2015: 94-97).

El guion intenta no alejarse del texto de Kazantzakis y para el propio Scorsese el resultado fue muy respetuoso con él, a pesar de todas las dificultades por las que pasó la producción, la postproducción y tras el escándalo posterior al estreno ${ }^{50}$. Pero, a pesar de esta pretendida (y patente) cercanía, en la película existen algunos cambios, omisiones o reducciones $^{51}$, decisiones lógicas si tenemos en cuenta la densidad y dimensión de la novela, inviable de adaptar al pie de la letra (y con un metraje de varias horas) para una producción cinematográfica. Por ejemplo, en la novela aparecen los personajes de José (padre de Jesús, paralítico por el impacto de un rayo) y su hermano, el rabino Simeón, pero no en la película. Por su parte, María (madre de Jesús) es tratada de manera somera en la cinta de Scorsese, con un papel bastante secundario y alejado de cualquier atisbo de santidad o divinidad, mientras que en la novela contaba con mayor profundidad, mostrándose como una mujer corriente y desdichada que llega a emitir reproches a su hijo ${ }^{52}$. Como recurso cinematográfico impactante creado más allá del texto del cretense, puede destacarse el plano en el que Jesús, tras el retiro en el desierto, se saca el corazón del pecho y se lo ofrece a sus discípulos, «raro momento

\footnotetext{
49 «Magdalena, la hija única del rabino, el hermano de su padre» (Kazantzakis, 2015: $159)$.

${ }^{50}$ «But in the end, despite the difficulties, not only in getting the film made but also in the uproar that followed its release; despite the fact that we were forced to go into production with a small budget and rush through the editing process-despite all those things, I think our film honored the spirit of Kazantzakis's book» (Scorsese, 2005: 230).

51 Una de las decisiones más patentes en la versión original de la película es mantener un lenguaje coloquial, una decisión de Scorsese para intentar no alejarse ni del texto de Kazantzakis ni de los Evangelios, pero hacer de los diálogos algo mundano y cercano a nuestros días (Vaquero, 2008: 248-249).

${ }^{52}$ Jesús, a su vez, proclama en el Gólgota su arrepentimiento por haber sido un mal hijo para su madre.
} 
onírico, ausente en la novela de Kazantzakis y que fue idea de Schrader» (Fernández Valentí, 2008: 87). De hecho, si hablamos de escenas o secuencias impactantes en la película que se recrean más que en la novela, no cabe duda de que el camino hacia el Gólgota y la crucifixión cumplen con este (afortunado) exceso. Ambas están desarrolladas con cuidado visual y buen acompañamiento con la música de Peter Gabriel, y en el propio momento de la crucifixión, además de los audaces movimientos de cámara, no hay que olvidar el gran realismo y cuidado en cuanto a los gestos de sufrimiento, el sudor, las heridas y la sangre ${ }^{53}$, e incluso la propia postura en la cruz ${ }^{54}$.

Pero el verdadero reto para comprender tanto la novela de Kazantzakis como la película de Scorsese llega en el pasaje que da nombre a ambas: la última tentación. No se trata de un simple golpe de efecto repentino o de un giro de guion inesperado, sino que se plantea de forma sutil, sugerente e interesante, y hasta el mismísimo final del metraje no se desvelará su verdadero significado. La escena que inicia este segmento se desarrolla silenciando el estruendo en el momento de la crucifixión, un recurso tan sencillo como efectivo para añadir un componente de extrañeza a lo que se ha desarrollado con anterioridad. El ángel de la guarda femenino quita de manera pausada los clavos que sujetan a Jesús a la cruz con sus propias manos y lo desciende mientras explica que lo está salvando con una extrañísima candidez. La escena es un lucimiento visual de la película de Scorsese, consiguiendo impactar al ampliar lo que en la novela ocupa apenas algunas líneas, con Jesús expirando al final del capítulo XXIX y despertándose en el XXX en un campo primaveral, donde se encuentra con el ángel.

A partir de entonces, el nuevo mundo que le muestra el ángel se caracteriza en la película por planos en los que se hace patente el verdor de las localizaciones de rodaje en el Atlas, que contrastan con los tonos ocres y amarillentos de los paisajes desérticos en los que se desarrolla el resto de la cinta. En esta nueva realidad Jesús puede emprender una vida humana normal cuyo primer acto es reencontrarse con Magdalena y yacer con ella (y dejarla embarazada), un pasaje de la novela y una escena en la película que sin duda pueden considerarse como de los más impactantes y alejados

\footnotetext{
${ }^{53}$ Pero siempre lejos del punto extremadamente sangriento (bordeando lo sádico o lo gore) al que más tarde llegó Mel Gibson con La Pasión de Cristo (2004).

${ }^{54}$ La peculiar postura que muestra Willem Dafoe en lo alto de la cruz, con las piernas flexionadas hacia un lado y la pelvis apoyada en un saliente de madera, está muy alejada de las representaciones aceptadas comúnmente en ámbitos religiosos y artísticos. Esta disposición se basa en los hallazgos arqueológicos de 1968 en la necrópolis de Fivat ha-Mivtar, en Jerusalén, en la cual, entre otros cadáveres, se encontraron los restos de un crucificado; el estudio de los mismos dio lugar a una interpretación de esta posible postura, recreada por el equipo de la película de Scorsese (García Iglesias, 1995: 27-30).
} 
de la ortodoxia cristiana ${ }^{55}$. Esta carnalidad entronca con el plan que María y Marta comentaron a Jesús tras volver de su retiro del desierto, el llegar a formar una familia y ser un humano más para honrar a Dios, una maniobra que no trata simplemente de subvertir uno de los mandamientos de la fe cristiana, sino que marca una extraña ruptura con el camino ascendente de Jesús hacia la divinidad que planteaba el cretense. Este camino estaba a punto de culminar con su sacrificio en la cruz, pero se interrumpe bruscamente y parece volver a la casilla de inicio, cuando Jesús era meramente el «hijo del carpintero» o, como mucho, el «hijo del hombre». Esta ruptura es por tanto una de las pruebas más claras de lo que pretendía Kazantzakis al plantear esta tentación posterior a la crucifixión, poner en duda la divinidad que iba a alcanzar Jesús, provocar incertidumbre en el lector (algo que Scorsese también consigue) y desmontar el embrollo justo al final del metraje, aclarando perfectamente que los hechos acaecidos no eran ni más ni menos que un paréntesis, un sueño en sus propias palabras. Otro momento de este pasaje que puede considerarse como heterodoxo es el de la reacción violenta de Jesús tras la muerte de Magdalena; pero se trata de otro de esos detalles igualmente al servicio del paréntesis planteado de manera bastante clara, cuando Jesús quiere blandir un hacha, tal como había hecho tras el retiro en el desierto simbólicamente contra Satanás. De hecho, el consejo del ángel de que no debe batallar a Dios, sino entregarse a María, la hermana de Lázaro, porque en realidad solo habría una mujer en el mundo ${ }^{56}$, vuelve a demostrar esa carnalidad ficticia a la que Jesús se entrega en la última tentación, incluido el adulterio que comete después al yacer con Marta (la otra hermana de Lázaro).

Llegados a este punto, es muy difícil no extrañarse ante la propuesta de Kazantzakis (y de Scorsese), que incluso parece demasiado simple, demasiado fácil, y que se sigue desarrollando con algo tan peculiar como

\footnotetext{
55 «El escándalo provocado por la contenida evocación de la sexualidad crística, por otra parte con una satisfacción nunca afirmada axiomáticamente sino remitida al ámbito irreal del paréntesis que significa la última tentación, se correspondería no tan sólo con la terca y herética resistencia frente a la veracidad de la naturaleza humana de Cristo, sino con el mantenimiento de un soterrado espíritu iconoclasta, especialmente vivo en el sector oriental del cristianismo, prolongado en la tradición de las iglesias reformadas y en la permanente desconfianza eclesial sobre la pregnancia del cine [...]. El rechazo a reconocer que Cristo no era un hombre mutilado o castrado se equipararía con la dificultad de asumir la capacidad funcional de sus atributos sexuales o la posibilidad de una relación sentimental con un personaje de dudosa reputación como María Magdalena, según el film empujada a la prostitución por culpa precisamente del rechazo de Cristo a satisfacer un amor originado en la infancia» (Monterde, 2000: 360).

${ }^{56}$ «En el mundo no hay dos mujeres, hay sólo una; una sola mujer con innumerables rostros. Y uno de estos rostros es el que viene, levántate para recibirla» (Kazantzakis, 2015: 687).
} 
Jesús teniendo cada vez más hijos y haciéndose anciano ${ }^{57}$. Aparece entonces la penúltima prueba de que nos encontramos en un paréntesis, cuando Jesús se encuentra con Saulo, el zelote sanguinario responsable de la muerte de Lázaro tras haber sido resucitado por el propio Jesús. Pero el zelote se ha convertido ahora en el predicador Pablo, cuyo discurso subvierte su placentera vida terrenal al predicar que era hijo de Dios y no de María, y mencionar tanto la crucifixión como la posterior resurrección que venía a redimir todos los pecados de la humanidad ${ }^{58}$. Salta a la palestra el choque entre las esencias humana y divina de Jesús, el campo de batalla en el que el escritor cretense basaba sus intenciones a la hora de escribir la novela, y tiene lugar entonces uno de los momentos de mayor tensión de la narración, cuando Jesús muestra su indignación ante las palabras de Pablo ${ }^{59}$ y el diálogo entre ambos se convierte en uno de los pasajes más esclarecedores sobre el pensamiento religioso de Kazantzakis. De hecho, para referirse a Jesús, el personaje de Pablo utiliza entonces por primera vez (casi al final de la novela y de la película) la palabra Cristo ${ }^{60}$. A Pablo le es indiferente que Jesús le desmienta su crucifixión y resurrección, porque el Cristo que él predica es mucho más importante y poderoso, es una exageración interesada para salvar el mundo ${ }^{61}$. El predicador es el recurso más directo que tiene Kazantzakis en toda la novela para criticar a la institución eclesiástica, pero no a la figura de Cristo ni a Dios. El cretense concentra en Pablo todo lo que él considera negativo en la doctrina

\footnotetext{
${ }^{57}$ En la novela llega incluso a cambiar su nombre por el de Lázaro, algo que no aparece en la película.

${ }^{58}$ «Jesús el nazareno -habrás oído hablar de él- no era hijo de José y de María, era hijo de Dios. Bajó a la tierra, se encarnó como hombre para salvar al hombre. Los inicuos sacerdotes y los fariseos lo prendieron, lo condujeron ante Pilato y lo crucificaron. Pero al tercer día resucitó y subió al cielo. ¡La muerte ha sido vencida, hermanos; los pecados han sido perdonados, las puertas del Paraíso se han abierto!» (Kazantzakis, 2015: 698-699).

${ }_{59}{ }$ ¿Embustero! ¡Embustero! -le gritaba-. Yo soy Jesús de Nazaret. Nunca fui crucificado. Nunca resucité; soy hijo de María y de José, el carpintero de Nazaret. No soy hijo de Dios, yo soy hijo de un hombre, como los demás. ¿Qué son esas blasfemias, esas infamias, esas mentiras? ¿Con semejantes falsedades te atreves a salvar el mundo canalla?» (Kazantzakis, 2015: 699).

${ }^{60}$ Recordemos, «ungido» $\mathrm{o}$ «Mesías» en griego clásico.

${ }^{61}$ «En medio de la podredumbre, la injusticia y la pobreza de este mundo, Jesús el Crucificado, Jesús el Resucitado, era el más preciado consuelo del hombre honrado y oprimido. Mentira o verdad, ¿qué me importa? ¡Basta con que el mundo se salve! [...] A mí me traen sin cuidado las verdades o las mentiras; si lo vi o no lo vi; si fue crucificado o no fue crucificado. Yo, a base de obstinación, de deseo y de fe, fabrico la verdad. No me esfuerzo por encontrarla; la fabrico. La fabrico más grande que la estatura del hombre, y así hago más grande al hombre. [...] Yo me convertiré en tu apóstol, lo quieras o no. Yo te fabricaré a ti, tu vida, tu enseñanza, tu crucifixión y tu resurrección como yo quiera. No te engendró José, el carpintero de Nazaret, te engendré yo, Pablo, el escribano de Tarso, en Cilicia» (Kazantzakis, 2015: 700$702)$.
} 
cristiana, toda la construcción interesada de los dogmas, incluidos los relacionados con la figura de Cristo y las distorsiones que sufriría en los primeros siglos de existencia del Cristianismo. Pero la elección de este personaje para este cometido no es fortuita, ni mucho menos, ya que concuerda con las investigaciones sobre la historia de la doctrina cristiana, que le otorgan una importancia capital:

Pablo de Tarso fue el responsable de introducir los profundos cambios que el mesianismo del Jesús histórico precisaba para que su mensaje fuera comprendido y aceptado en ámbitos más amplios que el estrictamente judío. Este proceso [...] se logró gracias a la divinización de Jesús, por una parte, y a una doble tendencia remodeladora de su mensaje. El Apóstol de los gentiles modificó la figura del Mesías, orientada sólo hacia la salvación de Israel, convirtiéndola en la de un Salvador universal, y transformó la doctrina de la venida inmediata del reino de Dios, del Jesús histórico, en una espera de la venida de Jesús como juez de vivos y muertos al final de los tiempos, prolongando el fin del mundo presente a un final de los tiempos que se aleja indefinidamente del mundo actual. Por tanto, para la investigación moderna, es el Apóstol de los gentiles quien, a partir de una reinterpretación global de la doctrina y la misión de Jesús de Nazaret reinterpretación que el propio tarsiota afirma que debe a una visión o conversión casi instantánea- se constituye en el creador y organizador consciente de una nueva Iglesia. Es Pablo quien edifica el nuevo conjunto del cristianismo como un nuevo sistema religioso que pasa de ser puramente geocéntrico a una fe cristocéntrica. Y éstos precisamente son los postulados de Casandsakis (Vilela Gallego, 2015: 89).

El segmento de la última tentación culmina cuando Jesús, moribundo, es acompañado por algunos de sus discípulos, como Pedro, Natanael (nombre alternativo de Bartolomé) o Juan. La prueba final del verdadero significado de todo el extraño pasaje posterior a la crucifixión llega a las líneas de la novela y a los planos de la película ${ }^{62}$ cuando Judas, el mayor soporte de Jesús, su amigo más cercano, a quien encomendó la misión de traicionarlo y completar la misión de Dios, le reprocha frente a su lecho de muerte que no llegara a sacrificarse, que no completara la guerra contra los romanos y contra Satanás, que se desviara del camino revolucionario ${ }^{63}$, y le desvela que el ángel de la guarda no es otro sino Satanás. La reacción

\footnotetext{
${ }^{62}$ Los diálogos de la película de Scorsese en este momento siguen muy de cerca los de la novela.

${ }^{63}$ «iTraidor! -volvió a gruñir-, ¡Desertor! Tu puesto estaba en la cruz. Ese era el lugar que te había asignado el Dios de Israel para combatir. Pero te inundó un sudor frío y en el momento en que entreviste ante ti a la muerte, ¡huiste a toda velocidad! ¡Corriste a meterte bajo las faldas de Marta y María, cobarde! ¡Hasta cambiaste de rostro y de nombre, falso Lázaro, para salvarte!» (Kazantzakis, 2015: 716).
} 
de Jesús ante la aparición de Judas ${ }^{64}$ es la última prueba con la que se hace consciente del engaño perpetrado por esa encarnación del diablo, que lo sometió a una última tentación justo antes de expirar. Tras volver a suplicar el perdón de Dios ${ }^{65}$, Jesús vuelve a aparecer en el Gólgota, crucificado, y comprende con gran alegría que ha superado esa tentación final $^{66}$, pudiendo cumplir finalmente la misión encomendada por Dios. La alegría contenida en el texto de Kazantzakis se convierte en la película de Scorsese en el impactante plano en el que Willem Dafoe sonríe y comprende que su misión se ha cumplido, justo antes de expirar en la cruz. El final es mucho más rico en la película que en el texto, ya que los recursos audiovisuales usados en ese momento apuntalan el fin del paréntesis y la catarsis alcanzada por Jesús y compartida con el espectador: en cuanto el crucificado cierra los ojos, comienzan a sonar los típicos gritos femeninos del tema «It is accomplished» de la banda sonora de Peter Gabriel, y la imagen se vela en planos coloridos hasta que las campanas y el resto del tema de Gabriel acompañan a los títulos de crédito finales, aportando un tono realmente eufórico y de plenitud.

De este modo, todo este paréntesis en la novela (y por extensión en la película) constituye una crítica directa a la distorsionada institucionalización del mensaje de Jesús. Se convierte en la prueba de Kazantzakis (y Scorsese) de que su superación de esta última tentación probaba que puede ser considerado como Mesías redentor de la humanidad sin necesidad de pasar por las modificaciones que Pablo, símbolo de la institución eclesiástica, proclama en ese segmento de la novela.

\section{CONSIDERACIONES FINALES}

Este texto pretende marcar las confluencias y divergencias entre la novela de Nikos Kazantzakis y la película de Martin Scorsese. Pero también, sin adentrarse en cuestiones meramente teológicas, analizar las opiniones sobre la religión cristiana que ambos autores plasmaron en sus obras, y así poder abordar las distintas cuestiones que generaron escándalo tras la aparición del libro y de su adaptación cinematográfica. Un escándalo que, no olvidemos, aún se mantiene en diversos ámbitos.

Aunque Vida y hechos de Alexis Sorbás sea quizá la obra más conocida de Nikos Kazantzakis, las implicaciones religiosas contenidas en La última tentación y, por suerte o por desgracia, el escándalo alrededor de ella, le

${ }^{64}$ En la novela el resto de discípulos terminan por atacar también a Jesús y abandonar su lecho de muerte, con la excepción del apóstol Tomás (Kazantzakis, 2015: 720-721).

${ }^{65}$ Un pasaje solucionado en la película con Jesús saliendo de su casa, arrastrándose, y postrándose en mitad de un paisaje desolador de incendios y gente huyendo.

66 «Una alegría salvaje, indomable, se apoderó de él. No, no era cobarde, ni desertor ni traidor. No, no. Estaba clavado en la cruz, se había mantenido íntegro hasta el fin, había cumplido su palabra» (Kazantzakis, 2015: 722). 
hacen ser merecedora de un interés primario en la obra del cretense. De hecho, la adaptación a la gran pantalla realizada por Scorsese, estrenada 37 años después de que Kazantzakis escribiera su novela, provocó un nuevo interés a nivel mundial en ella y en la obra en general del literato cretense, arrastrado principalmente por las nuevas polémicas suscitadas, pero también por la curiosidad de quienes quisieran replantearse ciertas opiniones en torno a la religión cristiana y a la figura de Cristo en concreto.

Que un escritor como Nikos Kazantzakis sufriera persecuciones políticas y religiosas por intentar plasmar en su novela sus inquietudes religiosas debería ser un hecho censurable por todos en aras de la libertad de pensamiento. Pero si, además, tenemos en cuenta que gran parte de las protestas pasaron por alto las intenciones del autor, las críticas se convierten en simplemente destructivas, y para nada constructivas. Por su parte, Martin Scorsese comprendió que el texto del escritor cretense le podría servir para expresar sus propias inquietudes religiosas, para recoger su imagen moderna de Cristo, que para nada trataba de ser blasfema y que, aunque se separara de la ortodoxia de las Sagradas Escrituras, no tenía por qué ser contraria a ellas, sino una reflexión libre sobre ellas. Pero el neoyorquino se encontró con una resistencia feroz y, lo que es peor, antes de comenzar el rodaje o de que se estrenara la película, lo cual es tan ilógico como fanático. Al final el tiempo le ha dado la razón a ambos autores por haber aportado sendas obras valientes que no pueden considerarse anticristianas, sino que simplemente revisaban de manera crítica a un personaje que no tiene por qué ser intocable. Teniendo en cuenta que una parte muy importante de las sociedades del planeta han basado de algún modo su pensamiento en la tradición religiosa judeocristiana y musulmana, no era descabellado pensar que la obra de Kazantzakis iba a causar numerosas reacciones desde diversos ámbitos sociales, al igual que después la película de Scorsese.

Pero, ¿buscaba Kazantzakis el escándalo? ¿Lo buscaba Scorsese? Hablamos de un escritor que no paró de reflexionar sobre la religión a lo largo de su vida, que buscó a Cristo y lo tomó como un ejemplo para superar los males del mundo en el siglo XX. Y de un cineasta de fuertes convicciones religiosas, un católico con temprana vocación sacerdotal, que vio una oportunidad irrepetible para ofrecerse a sí mismo y al mundo una imagen más humana y cercana a las personas corrientes de Cristo. La condición de ambos autores ya resulta suficientemente interesante y reveladora para que nos replanteemos la polémica suscitada por ambas obras, en las que no se puede hablar de blasfemia o sacrilegio, ni siquiera en el cuestionamiento de la fe de los creyentes, sino de una relectura en clave moderna de la figura de Cristo y de una crítica a la Iglesia.

Se ha criticado el componente extremadamente humano de Jesús tanto en la novela como en la película, pero el camino ascendente desde lo terrenal a lo divino está cerca del mensaje evangélico. Se han criticado los 
hechos narrados en el segmento de la última tentación, como el pasaje en el que Jesús yace con Magdalena, el discurso feroz de Jesús contra Dios por matarla, la justificación del adulterio o la bigamia con María y Marta, el haber tenido hijos y haber envejecido en vez de morir a los treinta y tres años en la cruz. Pero todo ello carece de valor en cuanto se demuestra al final de la narración que todo era un sueño, y que finalmente esa última tentación ha podido ser superada, permitiendo la consecución de la misión divina de la redención en la cruz.

Ciertamente ambos autores se salieron de los cánones establecidos, pero lo hicieron desde una postura respetuosa y reflexiva, con críticas (o, mejor dicho, posiciones) constructivas y no simplemente destructivas, con fervor cristológico heterodoxo en cuanto a la Iglesia oficial, pero ortodoxo en cuanto a sus conflictos y búsquedas interiores. Salirse del canon muchas veces es una auténtica prueba de fe que puede derivar en rechazo apriorístico y ciego. Y eso es un error, como lo fue intentar machacar a la novela y a su adaptación cinematográfica. Vistas con perspectiva, unos setenta y unos treinta años más tarde respectivamente, no cabe duda de que seguir atacándolas sin más es ser demasiado cuadriculado o inmovilista. Si nunca salimos de los límites preestablecidos, nunca avanzaremos como personas, ni como investigadores, ni como sociedad. Es el momento (siempre lo ha sido) de desterrar las polémicas irreflexivas, de aportar datos a todos, incluidos los extremistas, que ahorren enfrentamientos. Solo hace falta pensar, debatir, encontrar confluencias y no discursos únicos. Y dejarse llevar por las reflexiones de otros, pero tamizándolas desde la razón y desde el espíritu crítico.

\section{Bibliografía CITADA}

Aguado CAntabrana, Oskar (2020), «El "efecto Gladiator” 20 años después: cine "de romanos", Champions, memes y extrema derecha», Proyecto ANIHO-ANIWEH Project [En línea: https://aniho.hypotheses.org/2012. Fecha de consulta: 06/05/2020].

ANÓNImo (1988), «Escasos incidentes en el estreno en España de La última tentación de Cristo», El País, 15 de octubre [En línea: https://elpais.com/diario/1988/10/15/cultura/592873206 85021 5.html. Fecha de consulta: 24/01/2018].

Burnette-Bletsch, Rhonda (2019), «The Last Temptation of Christ: Scorsese's Jesus among Ordinary Saints», en C. B. Barnett y C. J. Elliston (eds.), Scorsese and Religion, Leiden/Boston, Brill, págs. 151170.

Contreras Guerrero, José David (2012), «Sobre la historicidad de la película "El discípulo" de E. Ruiz Barrachina», Arqueohistoria crítica [En línea: $\quad$ http://arqueohistoriacritica.blogspot.com/2012/11/eldiscipulo-2010-de-emilio-ruiz.html. Fecha de consulta: 02/05/2020]. 
Kazantzakis y Scorsese, dos autores frente a la controversia

DÁvila Vargas-MachuCA, Miguel (2017), «La Gran Manzana según Scorsese: de la infancia a la madurez», en G. Camarero Gómez (ed.), Ciudades americanas en el cine, Madrid, Akal, págs. 185-202.

ESPAÑA, Rafael de (2009), La pantalla épica. Los héroes de la Antigüedad vistos por el cine, Madrid, T\&B.

Fernández Valentí, Tomás (2008), Martin Scorsese: un infiltrado en Hollywood, Barcelona, Carena.

Ferreras Rodríguez, José Gabriel (2011), «Santos seculares: El debate religioso en el cine de Martin Scorsese», FRAME, 7, págs. 110-123.

Ferro, Marc (2008), El cine, una visión de la Historia, Madrid, Akal.

García Iglesias, Luis (1995), La Palestina de Jesús, Madrid, Historia 16.

KaZANTZAKIS, Nikos [CASANDSAKIS, Nicos] (2015), La última tentación (ed. de Carmen Vilela Gallego), Madrid, Cátedra.

Lindlof, Thomas R. (2008), Hollywood Under Siege: Martin Scorsese, the Religious Right, and the Culture Wars, Lexington, University of Kentucky Press.

MÉNDIZ, Alfonso (2009), Jesucristo en el cine, Madrid, Rialp.

Monterde, José Enrique (2000), Martin Scorsese, Madrid, Cátedra.

Pinuaga, Álvaro y Yannick VAn der VAart (2010), Rodamos historia, Madrid, T\&B.

Riera GinesTAR, Joaquín (2017), El Jesús de la historia: un acercamiento a través del evangelio de Tomás, Córdoba, Almuzara.

SCORSESE, Martin (2005), «On Reappreciating Kazantzakis», en D. J. N. Middleton (ed.), Scandalizing Jesus?: Kazantzakis's «The Last Temptation of Christ» Fifty Years On, New York/London, Continuum, págs. 229230.

Solomon, Jon (2002), Peplum. El mundo antiguo en el cine, Madrid, Alianza.

Sotinel, Thomas (2010), Martin Scorsese, París, Cahiers du Cinéma Sarl.

STAVRU, Pátroclos (2015), «Nota informativa del editor-responsable de la edición», en N. Kazantzakis [N. Casandsakis], La última tentación, Madrid, Cátedra, págs. 725-767.

Vaquero ArgelÉs, María (2008), «La última tentación de Cristo», en G. Camarero Gómez, V. de Cruz Medina y B. Heras Herrero (coords.), I Congreso Internacional de Historia y Cine, Madrid, Universidad Carlos III, págs. 245-257.

Vilela Gallego, Carmen (2015), «Introducción», en N. Kazantzakis [N. Casandsakis], La última tentación, Madrid, Cátedra, págs. 7-123.

Fecha de recepción: 28/05/2020.

Fecha de aceptación: 25/07/2020. 